\title{
On the stability of risk and time preferences amid the COVID-19 pandemic
}

\author{
Andreas C. Drichoutis ${ }^{1}$ D $\cdot$ Rodolfo M. Nayga Jr. ${ }^{2}$
}

Received: 26 November 2020 / Revised: 23 July 2021 / Accepted: 29 July 2021 /

Published online: 13 August 2021

(c) Economic Science Association 2021

\begin{abstract}
We elicited incentivized measures of risk and time preferences from a sample of undergraduate students in Athens, Greece, in waves that preceded and overlapped with the COVID-19 pandemic. We exploited the timing of several events that occurred in the course of the pandemic (e.g., first occurrence of cases and deaths, curfew, relaxation of curfew etc.) and estimated structural parameters for various theories of risk and time preferences comparing these with pre-pandemic estimates. We find no effect between the different waves or other key events of the pandemic, despite the fact that we have about 1000 responses across all waves. Overall, our subjects exhibit intertemporal stability of risk and time preferences despite the significant effect of the COVID-19 pandemic on public health and the global economy.
\end{abstract}

Keywords Time preferences $\cdot$ Discount rates $\cdot$ Risk preferences $\cdot$ Pandemic $\cdot$ Natural disaster

JEL Classifications C90 · D12 · D81 · D91 · Q54

We would like to thank the Editor and two anonymous reviewers for helpful comments and suggestions that greatly improved our manuscript. Data and codes to replicate the analysis and results reported in the paper have been deposited at the Open Science Framework: https://osf.io/ sqk4a/.

Andreas C. Drichoutis

adrihout@aua.gr

Rodolfo M. Nayga Jr.

rnayga@tamu.edu

1 Department of Agricultural Economics and Rural Development, School of Applied Economics and Social Sciences, Agricultural University of Athens, Iera Odos 75, 11855 Athens, Greece

2 Department of Agricultural Economics, Texas A\&M University, College Station, TX 77845, USA 


\section{Introduction}

Economic theory suggests that a broad set of decisions relating to important outcomes such as savings, investments, insurance, retirement plans, occupational choices, labor supply, health services purchase, health behaviors and other aspects of everyday life, can be explained by differences in agents' budget constraints as well as Risk and Time Preferences (RTPs). RTPs are at the crux of consumer behavior and in standard economic analysis, individual preferences are considered to be stable over time. Andersen et al. (2008b) argue that the assumption of stable preferences lies in the ability to assign causation between changing opportunity sets and choices in comparative statics exercises or, in Stigler and Becker's (1977) words, 'no significant behavior has been illuminated by assumptions of differences in tastes'.

The assumption of stability of RTPs has been challenged however by the empirical literature. For example, Chuang and Schechter (2015) find weak evidence of stability in experimental measures of time preferences, although they find strong evidence of non-stability of experimental measures of risk preferences over time. Schildberg-Hörisch (2018) take the view that the extent to which preferences are stable is ultimately an empirical question. It is therefore of great importance for the study of economic outcomes to understand whether RTPs are a stable individual characteristic, change over time, or whether they are affected by various negative shocks, such as financial crises, trauma from conflict, natural disasters or a pandemic.

Andersen et al. (2008b) stressed the conceptual distinction of temporal stability of preferences as either having the same preferences over time (unconditional stability) or as preferences being a stable function of states of nature and opportunities that change over time (conditional stability). They proclaim the latter as the right metric since conditional temporal stability can be very important for populations with heterogeneous preferences. We adopt this approach in our study as well. ${ }^{1}$

Our study focuses on the negative shock of the COVID-19 pandemic (caused by SARS-CoV-2) which has been extremely disruptive to public health and the global economy. $^{2}$ We originally set up our study in 2017 with the purpose of administering, on an annual basis, a battery of incentivized and unincentivized measures to the student population of the Agricultural University of Athens, Greece. Each year since 2017, we administered the exact same battery of measures to students of the university that had voluntarily enrolled to participate in surveys/experiments. Students were invited to participate in an online survey via Qualtrics and were invited to participate in batches in order to achieve a good spread of responses across the one and a half months that the elicitation took place. The original purpose of the study was to elicit a battery of psychological, behavioral

\footnotetext{
1 As an alternative method, Harrison et al. (2020) explore conditional stability of risk preferences but by looking at the stability of distributions, where the distributions derive econometrically from random coefficient models in order to incorporate heterogeneity of responses.

${ }^{2}$ In this respect, our study adds to a stream of literature that examines the effect of major negative shocks on people's preferences. We review some of these studies in the Electronic Supplementary Material in Section C.
} 
and economic measures and traits that could be later matched with data from laboratory experiments conducted at the premises of the university. The study was initiated in 2017 and was then repeated annually at similar dates every year. About halfway the 2020 wave, our study was re-designed due to the COVID-19 pandemic. The first case of COVID-19 was confirmed on February 26 in the country and on March 12 the first death occurred which coincided with the end of the originally planned study for 2020.

We decided to re-launch our study and invite back all subjects that had participated in the 2019 and the early 2020 wave. The re-launch of the study on March 23, 2020 coincided with a general curfew imposed by the government banning all nonessential transport and movement across the country. We extended the duration of the study until a few weeks after the opening up of the economy and restart of business activity. Thus, for a considerable number of subjects (we have more than 1,000 responses over the three waves), we have their response before the pandemic, during the pandemic, and after successfully flattening the curve of cases/deaths. This successful flattening of the curve was followed by a second phase of the pandemic that started building up during the summer and received exploding dimensions in Autumn, leading to a second curfew that was imposed on November 7, 2020. In terms of cases and deaths, the first phase of the pandemic was minuscule when compared to the second phase (see Figure A1b in the Electronic Supplementary Material). ${ }^{3}$

Our study adds to the emerging stream of studies that examine how risk or time preferences have evolved over the course of the pandemic. Angrisani et al. (2020) study the stability of risk preferences by comparing choices in the Bomb Risk Elicitation Task (Crosetto and Filippin 2013) from undergraduate students (60 subjects) as well as professional traders and portfolio managers (48 subjects) in London. They elicited subjects' choices before the pandemic in 2019 as well as on a specific 13-day time window in April 2020 when London was in a lock-down. They find no change in risk preferences during the pandemic.

Shachat et al. (2021) administered incentivized lottery choice tasks in the gain and loss domain to 396 students from Wuhan University, that were equally split among five waves (79 subjects/wave). Data for each wave were collected right after key events starting in January 2020 and up to March 2020 (when WHO declared it a global pandemic) and were also contrasted to pre-pandemic data from May 2019. They observed significant increases in risk tolerance (risk is measured based on the switching point in the lottery choice tasks) during the early stages of the COVID-19 crisis.

Lohmann et al. (2020) administered incentivized lottery choice tasks, incentivized convex time budgets and hypothetical investment games (investments that

\footnotetext{
3 The Electronic Supplementary Material contrasts the number of cases/deaths from February 2020 to February 2021 with Google's COVID-19 Community Mobility Reports which tracks mobility to work, retail, parks etc. It is evident that in the second curfew some adaptation to the situation had occurred. This renders more likely a stronger effect on risk/time preferences in the first phase of the pandemic where people came across an unprecedented shock. Nevertheless, given the absence of evidence during the second and deadlier phase of the pandemic in the country, we refrain from making absolute and generalized statements about the effect of the pandemic on risk and time preferences.
} 
offered higher returns as well as chances of losing the investment) to student subjects from Beijing universities. Subjects participated in online surveys in October 2019 (wave 1), December 2019 (wave 2) and March 2020 (wave 3). In the third wave, subjects had been geographically scattered in various areas of China and Lohmann et al. (2020) use the balanced sample of 539 subjects along with information about virus exposure in the geographical region of subjects' area to examine potential effects on preferences. They find no significant changes in either risk or time preferences across waves.

Harrison et al. (2020) elicited atemporal risk aversion, intertemporal risk aversion and time preferences from 598 students at Georgia State University, USA. Subjects were split over the course of the pandemic to $112,130,117,99,81$ and 59 subjects in each of five waves, respectively, for the period from May to October 2020. They also have pre-pandemic data from 2019 for atemporal risk preferences for 232 subjects that were common to the COVID-19 experiment, as well as for time preferences for subjects drawn from the same population but they do not overlap with the COVID-19 experiment. Overall, they find that time preferences and intertemporal risk preferences are stable over the course of the pandemic. They also find that subjects become more atemporal risk averse during the pandemic under an RDU model but not under EUT. This points to the importance of having risk measures that allow one to model the structure of risk preferences which is impossible to achieve with survey measures or even with incentivized tasks that do not admit structural estimation of atemporal risk preferences.

Gassmann et al. (2020) elicit preferences for risk, ambiguity as well as time preferences from students at Burgundy in France. They collected data from 596 subjects split in three waves: during lockdown (217 subjects), after the lockdown (190 subjects) and four months later (189 subjects). They also have responses from prepandemic data that were collected in 2016. Gassmann et al. (2020) report decrease in patience, less risk aversion, less ambiguity aversion and less prudence during the lockdown. One should note however, that incentives in their study had a very small chance (1\%) of being realized, so results should be viewed within this context.

Li et al. (2021) administered several games and individual choice tasks to student subjects at Xiamen University in July 2019. This first wave collected responses from 633 subjects that were seated in a large auditorium and the exact same games and tasks were repeated with a subsample of 585 of them in July 2020. The authors analyze the number of safe choices subjects did in a Holt and Laury (2002) type of task and find that subjects made more safe choices in the midst of the pandemic; i.e., they were more risk averse.

Table 1 summarizes the attributes of the various studies in this literature and compares these with our study. ${ }^{4}$ One unique feature of our study is that in each wave, we collected responses for a period longer than one and a half months, allowing us to record multiple key events in the timeline of the pandemic. Given that most studies are focused on samples from China and only two of them measure time preferences,

\footnotetext{
4 A couple more studies are relevant (Ikeda et al. 2020; Bu et al. 2020) but since they only used hypothetical incentives, we do not review these studies here.
} 


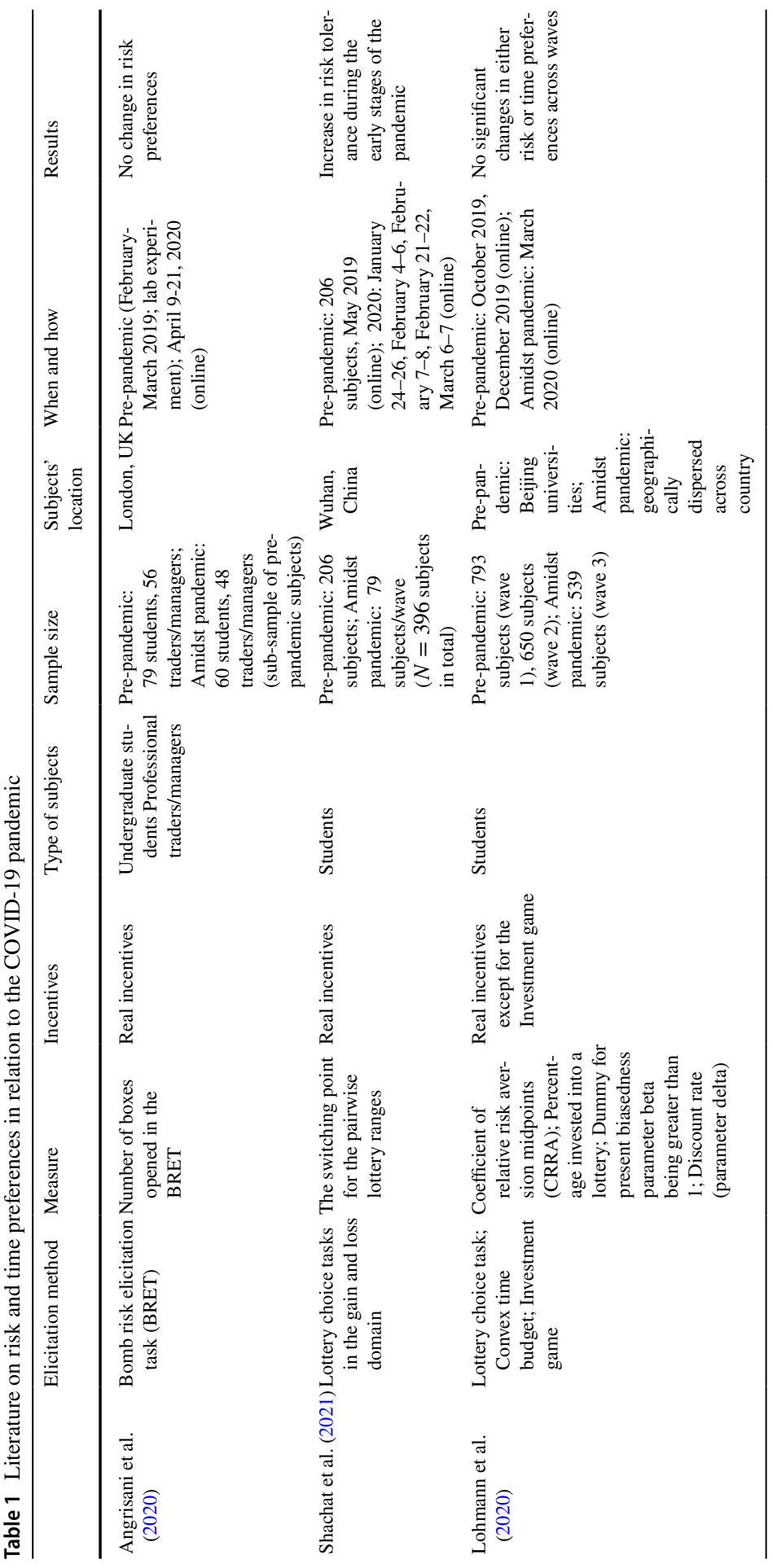




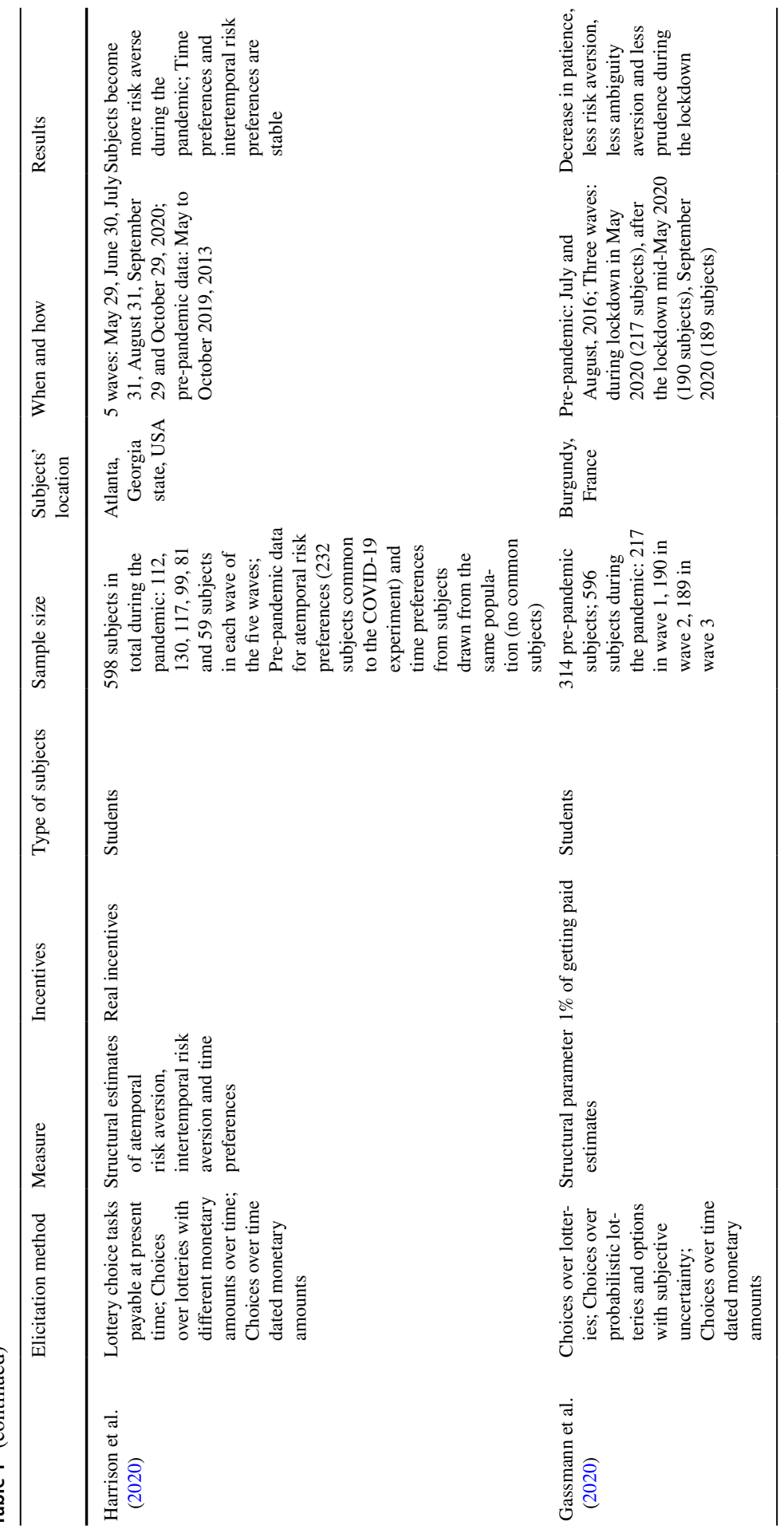




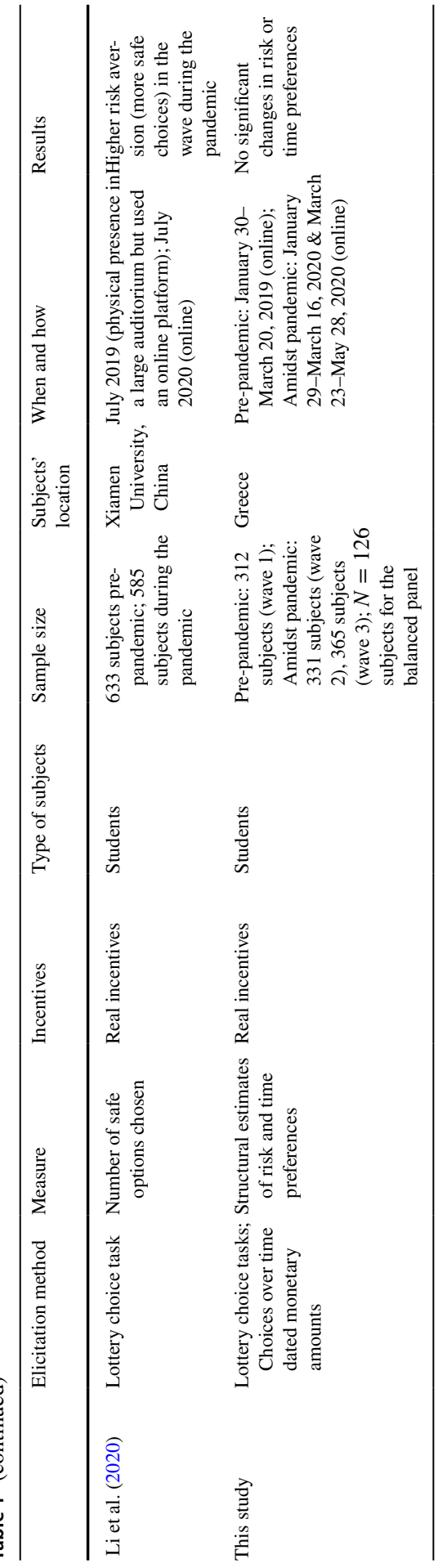


our study is the only one providing structural estimates for risk and time preferences for subjects from Europe where we provide salient incentives to subjects. Harrison et al. (2020) also estimate structural parameters but for USA students. Gassmann et al. (2020) provide insights for French students although Harrison et al. (2020) note that these choices should be viewed as hypothetical for practical purposes. Furthermore, our sample size is fairly large for an incentivized study, and using students as our workhorse is not at odds with what almost all other studies cited in Table 1 did. Snowberg and Yariv (2021) compare a sample from almost the entire undergraduate population of the California Institute of Technology with a representative sample of the USA population and an Amazon Mechanical Turk sample. They find that the student population exhibits less noise as compared to the other samples and while large differences in behaviors are observed, these differences had limited impacts on comparative statics and correlations between behaviors.

Using a student sample to study stability of preferences during the pandemic is a direct result of being fortunate enough to be doing experiments with this specific sample when the pandemic started. However, students remain a sample of convenience and one critique might be that student subjects were better able to shield themselves from the risks of exposure to COVID-19 by staying at home, attending classes remotely etc. Other groups of subjects, like front-line health professionals, workers in essential public services, retail and manufacturing sector workers were not able to stay at home or work remotely. Thus, we cannot claim that results from our study are generalizable to the population. Nevertheless, our study contributes to this stream of research that will allow other researchers to build a complete picture of how the pandemic impacted people of various occupations in different parts of the world.

Our paper is structured as follows. In Sect. 2, we provide details about the design of the study and elicitation of risk and time preferences. In the same section, we also provide information about how the COVID-19 pandemic evolved in the country of our study (Greece) as well as present how we go about with our structural econometric methods to model key parameters from the theory of RTPs. Results and various robustness checks specifications are presented in Sect. 3. We conclude and discuss our results in the last section.

\section{Survey design}

\subsection{Sample and quality control}

An online questionnaire was administered annually to the population of students registered in the online recruitment software (ORSEE) of the university (Greiner 2015), using the Qualtrics platform. The first wave started in 2017 and invitations were sent out gradually on a rolling basis, starting from late January to mid March. 
Similar days and dates were selected for the next waves administered in years 2018, 2019 and $2020 .^{5}$

Subjects could take the survey anytime they wanted once they received an invitation to participate, but had a limited time window to complete the survey once they started. Figure 1a shows the number of responses per day in the 2019 wave-one year before the outbreak of the pandemic in the country. Similarly, Fig. 1b shows responses per day for the 2020A wave which was planned to conclude by March 17, 2020. As can be seen, halfway through the 2020A wave, the first case of COVID-19 was confirmed (February 26, 2020) and the first death occurred (March 12, 2020). Given the rapid development of subsequent cases and deaths, we decided to launch an additional wave (2020B wave) where we invited the union of subjects that had participated in the 2019 and 2020A waves to participate again. Our study was preregistered in AsPredicted and a copy of the publicly available file can be found in the Electronic Supplementary Material. The start of the 2020B wave coincided with the enactment of a general curfew (March 23, 2020) banning all nonessential transport and movement across the country. Invitations to participate in the 2020B wave were distributed throughout the period of the curfew (where cases and deaths increased) as well as for almost a month after the curfew was relaxed (relaxation started on May 4, 2020) when the curve of cases and deaths had been flattened.

The recruiting procedure was similar for every wave and worked as follows. First, a list of valid email addresses was compiled (along with names and surnames) using as source the list of the universe of active students that are voluntarily registered through the ORSEE recruiting system (Greiner 2015). Email invitations were then sent in batches, scheduled for two times a week, covering a period of approximately one and a half months. A reminder email was sent two days after a batch of emails was first sent. Students are identified by their unique student ID number and at the conclusion of the survey, they were asked to upload a picture of their student ID for verification. Given that all waves included incentivized tasks of risk and time preferences (described momentarily), money transactions were ordered only when their ID was confirmed following a manual cross verification procedure by one of the investigators. Moreover, the invitation email emphasized several times that the invitation link is unique and that subjects must not forward their participation link to other subjects. ${ }^{6}$ Given that the risk/time preferences tasks were part of a larger battery of questions and that subjects knew they would be asked for verifiable data in order to be paid, it is unlikely that other subjects but the intended recipients would answer a given questionnaire. Thus, we can be very confident that subjects with a given ID number are the same subjects answering the questionnaire throughout the different waves of the survey.

\footnotetext{
5 The start of the survey was selected to be exactly 50 days from the payment of the sooner option of the time preferences tasks that was always selected to be a working day (a Thursday) so that payments could be delivered.

${ }^{6}$ The general principle was that we excluded and did not pay a subject if their ID listed a different person than the name we had sent the email to.
} 
(a) 2019 wave

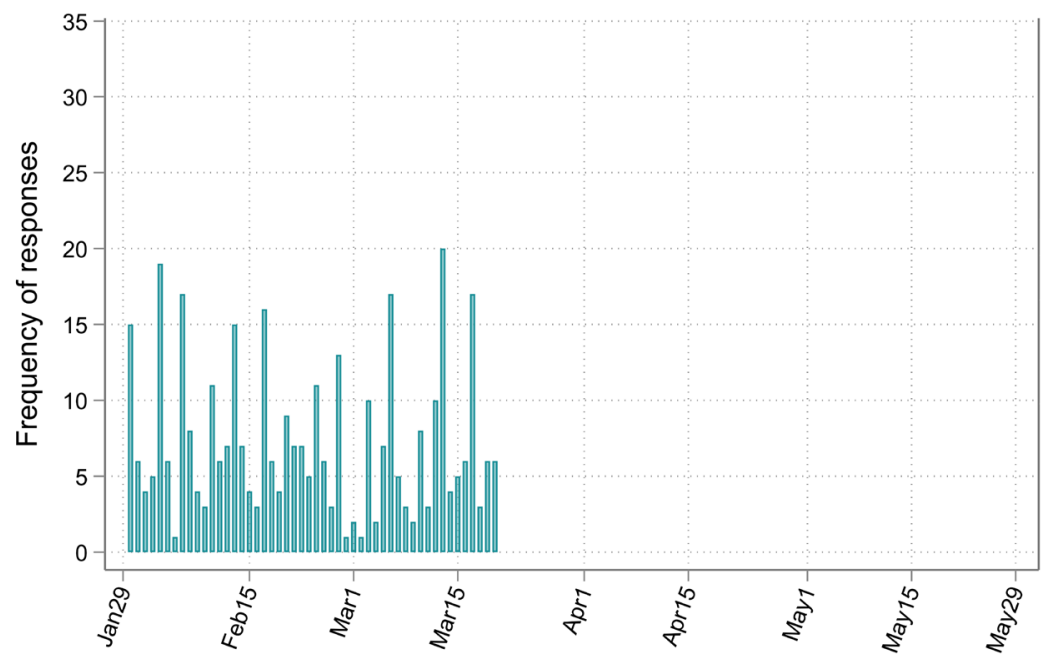

(b) 2020 waves

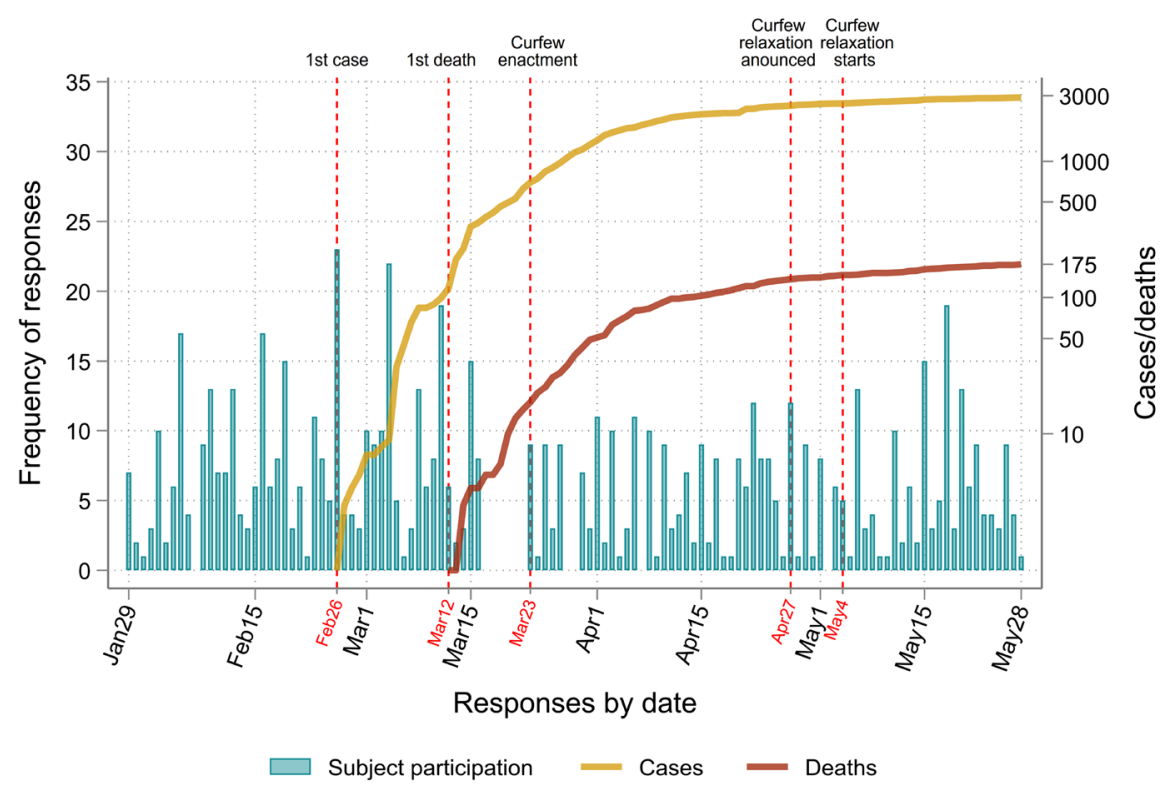

Notes: The number of cases/deaths from COVID-19 are depicted in log scale.

Fig. 1 Number of subjects per wave and day of the waves

In total, we were able to collect 1103 responses over the three waves (2019, 2020A and 2020B). Two responses were excluded because they were from a different person than the intended recipient of the invitation email. Ninety responses 
Table 2 Number of subjects per wave

\begin{tabular}{lcccc|c}
\hline \hline & \multicolumn{4}{c}{ Wave } \\
Participated in ... & 2019 & $2020 \mathrm{~A}$ & $2020 \mathrm{~B}$ & Total \\
\hline one wave & 69 & 36 & 3 & 108 \\
two waves & $\underbrace{117}_{2}$ & $\underbrace{169}$ & 236 & 522 \\
all three waves & 126 & 126 & 126 & 378 \\
\hline Total & 312 & 331 & 365 & $\mathbf{1 , 0 0 8}$ \\
\hline \hline
\end{tabular}

The numbers below the brackets indicate how subjects that participated in two waves are allocated to the waves. For example, while 117 subjects from the 2019 wave participated in two waves, 25 of them also responded in the 2020A wave. Similarly, of the 169 subjects that responded in two waves in the 2020A wave, 144 of them responded in the $2020 \mathrm{~B}$ wave as well. It is implied that 92 subjects $(=117-25$ or $=236-144$ ) participated in both the 2019 and $2020 \mathrm{~B}$ waves

were excluded because subjects stopped the questionnaire before reaching the risk/ time preferences elicitation tasks which renders them useless for the purpose of the present paper. Three more persons were excluded because their age or household size contained implausible values and their responses were deemed of ambiguous quality. Table 2 shows the number of responses per wave as well as the number of unique subjects that participated across one, two or all three waves. In all, we have 1008 responses that come from 495 unique subjects.

\subsection{The COVID-19 pandemic in Greece}

The COVID-19 pandemic in Greece started with the first confirmed case on February 26,2020 , when a 38-year-old woman who had recently visited Milan, Italy, was confirmed to be infected. ${ }^{7}$ Subsequent cases in late February and early March were related to a group of pilgrims who had traveled to Israel and Egypt (and their contacts) as well as to persons who had traveled to Italy.

The first death from COVID-19 occurred on March 12 in Greece. With subsequent cases and deaths occurring at a faster rate, the government started imposing gradual restrictions on movements and gatherings: all educational institutions were closed starting on March 11, flights from Northern Italy (March 9) and the whole of Italy (March 14) were banned, borders with Albania and North Macedonia were closed (March 16), and nonessential transport and movement across the country was banned (March 23). ${ }^{8}$ During this period many businesses and workplaces were also shutdown: theatres, hotels, courthouses, cinemas, shopping centres, cafes,

\footnotetext{
7 The virus in Milan had spread through the Lombardy cluster of cases. The first cases were confirmed on February 21 (Anzolin and Amante 2020), but had been circulating undetected much earlier. It was subsequently reported that the origin of these cases were connected to the first European local transmission that occurred in Munich, Germany as early as January 19, 2020 (Luna 2020).

${ }^{8}$ Movement was permitted only for a pre-specified set of reasons: moving to and from work, grocery shopping, visiting a doctor or assisting a person in need of help, outdoor exercising etc.
} 
restaurants, bars, museums and archaeological sites, with the exception of supermarkets, pharmacies and food outlets that were allowed to offer take-away and delivery only.

Following a successful flattening of the curve (see Fig. 1b), the government announced on April 27 a plan for the gradual lifting of the restrictive measures and the restart of business activity. Starting on May 4, the curfew was relaxed and subjects did not need a special permit to commute within their regional unit while retail-shops, coffee-places and restaurants gradually re-opened for business but with specific rules in place that they had to abide upon.

\subsection{Incentivized elicitation of risk preferences}

Subjects' risk preferences were elicited using the Holt and Laury (2002) task (HL) as well as a payoff varying task (PV). Drichoutis and Lusk (2016) have shown that greater predictive performance of choices can be achieved by combining information from the HL task and a PV task. This is because the HL task varies the probabilities of the lottery choices and provides a better approximation of the curvature of the probability weighting function (given that subjects weigh probabilities non-linearly), while the PV task varies the monetary amounts and is better in approximating the curvature of the utility function. In the HL task, individuals are asked to make a series of 10 decisions between two lottery options (see Table 3). Table 4 shows a payoff varying task that keeps the probabilities constant across the 10 decision tasks and instead changes the monetary payoffs across the 10 tasks. Both tasks are constructed in a way that the expected value of lottery A exceeds the expected value of lottery B for the first four decision tasks. Thus, a risk neutral person under Expected Utilty Theory (EUT) should prefer lottery A for the first four decision tasks and then switch to lottery B for the remainder of the decision tasks. ${ }^{9}$

Choices were not presented all together in a table form, but each choice was presented separately showing the probabilities and prizes as in Andersen et al. (2014). ${ }^{10}$ Subjects could indicate whether they preferred lottery A, lottery B or whether they are indifferent between the lotteries, in which case they were told that the computer would randomly decide the binding lottery to determine their payouts. The order of appearance of the HL and PV tasks were randomized across the subjects. An example of one of the decision tasks for the HL task is shown in Fig. 2 and the instructions for this task can be found in the Electronic Supplementary Material in Section A.

For each subject, one of the choices was randomly chosen and paid out after we added a $€ 2$ participation fee and we cross validated their student ID. Monetary

\footnotetext{
9 With the HL task, one can utilize two or more sets of MPLs with different monetary outcomes in order to get more points "on" the utility function. Alternative approaches that scale up payoffs primarily allow one to test for non-CRRA behavior, as in the Expo-Power utility specification that HL used.

${ }^{10}$ It is likely that presenting each pair of lotteries in a single screen allows subjects to focus more on a specific pair of lotteries, while presenting all pairs of lotteries arrayed in a table makes subjects to think the whole choice set as a single task.
} 
payouts were paid via bank transfer to subject's preferred bank account. ${ }^{11}$ All transactions were ordered after cross validation of their IDs was performed, which was normally within a few minutes after they completed the questionnaire.

For a subset of observations (49 observations from 45 subjects), payments could not be completed because subjects failed to complete the questionnaire and provide us with a valid mobile phone number, although we do have their complete responses from the risk and time preferences tasks. ${ }^{12}$ In addition, if a transaction would not go through, we would try to resend the money for a maximum of two times or until we resolved the problem with the transaction (in case the person would contact us to indicate there was a problem with the transaction). For 81 observations coming from 75 subjects, transactions were not completed even though we tried repeatedly to send the money. Finally, 878 transactions ( $87.1 \%$ of all observations) from 442 subjects were completed. Based on the 878 transactions, subjects were paid on average $€ 4.4$ (S.D. $=2.62, \min =2.1, \max =17$ ). ${ }^{13} \mathrm{We}$ should note beforehand that our results are invariant when using the full sample or just the constrained sample of subjects that accepted the payment. Thus, this should alleviate any concerns that the subjects who did not accept the payment may have treated the tasks as hypothetical and thus behaved differently.

\subsection{Incentivized elicitation of time preferences}

The experimental design for eliciting time preferences is based on the experiments of Coller and Williams (1999), Harrison et al. (2002) and Andersen et al. (2008a). Subjects were confronted with the payoff options listed in Table 5. In Table 5, option A (the principal) offers either a $€ 60$ or a $€ 90$ sooner option. Option B offers an amount $x 190$ days later, where $x$ ranged from annual interests rates of $5 \%$ to $50 \%$ on the principal, compounded semi-annualy. The sooner option (option A) was delivered on March 21 in the 2019 wave, March 19 in the 2020A wave, and June 1 on the $2020 \mathrm{~B}$ wave. ${ }^{14}$ The later option (option B) was delivered 190 days later. These choices also offered the option of stating indifference between the options, in which case subjects knew that a random draw would decide the binding option. Another set of choices also included a middle option which split the 190 days interval in two halves. Consequently, the middle option was delivered 95 days later than option A. The purpose of the latter task was to construct a choice set with fewer choices (choices 21 to 30 in Table 5) that is similar to choice tasks 1 to 20 in Table 5.

\footnotetext{
11 We used the 'Pay a friend' service of the bank 'Eurobank' which allows transferring money to subject's preferred bank account without knowing subject's account number, only by using an email address or a mobile phone number. The service is similar to the Zelle service operated by the Wells Fargo bank in the United States.

12 For the same reason, we do not have complete demographic and attitudinal information for all subjects.

13 Note that because subjects repeatedly participated in the three waves, many of them were paid for more than one time.

14 All dates and days were carefully pre-selected to be working days so that the payments could be physically delivered to subjects.
} 
Table 3 The Holt and Laury (2002) risk preference task

\begin{tabular}{|c|c|c|c|c|c|c|c|c|c|c|}
\hline \multicolumn{4}{|c|}{ Lottery A } & \multicolumn{4}{|c|}{ Lottery B } & \multirow[t]{2}{*}{$\mathrm{EV}_{\mathrm{A}} €$} & \multirow[t]{2}{*}{$\mathrm{EV}_{\mathrm{B}} €$} & \multirow[t]{2}{*}{ EV difference } \\
\hline$p$ & $€$ & $p$ & $€$ & $p$ & $€$ & $p$ & $€$ & & & \\
\hline 0.1 & 2 & 0.9 & 1.6 & 0.1 & 3.85 & 0.9 & 0.1 & 1.640 & 0.475 & 1.165 \\
\hline 0.2 & 2 & 0.8 & 1.6 & 0.2 & 3.85 & 0.8 & 0.1 & 1.680 & 0.850 & 0.830 \\
\hline 0.3 & 2 & 0.7 & 1.6 & 0.3 & 3.85 & 0.7 & 0.1 & 1.720 & 1.225 & 0.495 \\
\hline 0.4 & 2 & 0.6 & 1.6 & 0.4 & 3.85 & 0.6 & 0.1 & 1.760 & 1.600 & 0.160 \\
\hline 0.5 & 2 & 0.5 & 1.6 & 0.5 & 3.85 & 0.5 & 0.1 & 1.800 & 1.975 & -0.175 \\
\hline 0.6 & 2 & 0.4 & 1.6 & 0.6 & 3.85 & 0.4 & 0.1 & 1.840 & 2.350 & -0.510 \\
\hline 0.7 & 2 & 0.3 & 1.6 & 0.7 & 3.85 & 0.3 & 0.1 & 1.880 & 2.725 & -0.845 \\
\hline 0.8 & 2 & 0.2 & 1.6 & 0.8 & 3.85 & 0.2 & 0.1 & 1.920 & 3.100 & -1.180 \\
\hline 0.9 & 2 & 0.1 & 1.6 & 0.9 & 3.85 & 0.1 & 0.1 & 1.960 & 3.475 & -1.515 \\
\hline 1 & 2 & 0 & 1.6 & 1 & 3.85 & 0 & 0.1 & 2.000 & 3.850 & -1.850 \\
\hline
\end{tabular}

EV stands for expected value

Table 4 The payoff varying risk preference task

\begin{tabular}{|c|c|c|c|c|c|c|c|c|c|c|}
\hline \multicolumn{4}{|c|}{ Lottery A } & \multicolumn{4}{|c|}{ Lottery B } & \multirow[t]{2}{*}{$\mathrm{EV}_{\mathrm{A}} €$} & \multirow[t]{2}{*}{$\mathrm{EV}_{\mathrm{B}} €$} & \multirow[t]{2}{*}{ EV difference } \\
\hline$p$ & $€$ & $p$ & $€$ & $p$ & $€$ & $p$ & $€$ & & & \\
\hline 0.5 & 1 & 0.5 & 1 & 0.5 & 1.2 & 0.5 & 0.2 & 1.00 & 0.70 & 0.300 \\
\hline 0.5 & 1.2 & 0.5 & 1 & 0.5 & 1.5 & 0.5 & 0.2 & 1.10 & 0.85 & 0.250 \\
\hline 0.5 & 1.4 & 0.5 & 1 & 0.5 & 1.8 & 0.5 & 0.2 & 1.20 & 1.00 & 0.200 \\
\hline 0.5 & 1.6 & 0.5 & 1 & 0.5 & 2.2 & 0.5 & 0.2 & 1.30 & 1.20 & 0.100 \\
\hline 0.5 & 1.8 & 0.5 & 1 & 0.5 & 2.9 & 0.5 & 0.2 & 1.40 & 1.55 & -0.150 \\
\hline 0.5 & 2.0 & 0.5 & 1 & 0.5 & 3.5 & 0.5 & 0.2 & 1.50 & 1.85 & -0.350 \\
\hline 0.5 & 2.2 & 0.5 & 1 & 0.5 & 4.6 & 0.5 & 0.2 & 1.60 & 2.40 & -0.800 \\
\hline 0.5 & 2.4 & 0.5 & 1 & 0.5 & 6.8 & 0.5 & 0.2 & 1.70 & 3.50 & -1.800 \\
\hline 0.5 & 2.6 & 0.5 & 1 & 0.5 & 9.2 & 0.5 & 0.2 & 1.80 & 4.70 & -2.900 \\
\hline 0.5 & 2.8 & 0.5 & 1 & 0.5 & 15 & 0.5 & 0.2 & 1.90 & 7.60 & -5.700 \\
\hline
\end{tabular}

EV stands for expected value

The tasks always impose a front-end delay on the early payment (option A) which comes with two advantages. First, it avoids the passion for the present that decision makers exhibit when offered monetary amounts today or in the future by holding the transaction costs of future options constant (see Coller and Williams 1999, for a discussion). Second, it allows us to equalize the credibility of future payments because of the uncertainty associated with the receipt of later rewards. A caveat of not having time preferences choices with a zero FED is that we cannot estimate the quasi-hyperbolic discounting model with our data. Payments were promised to be paid with meal vouchers issued by an international company, redeemable in a wide network of supermarkets, restaurants, coffees 


\section{Choice 4}

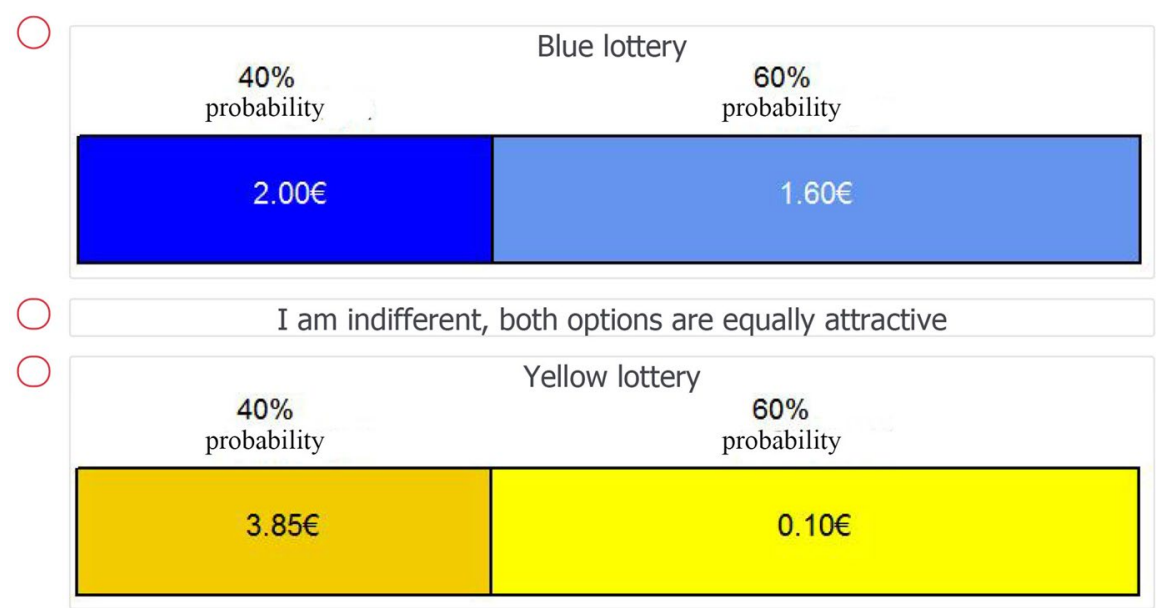

Fig. 2 Example screen for lottery choices

shops etc in the country and all payments were guaranteed by a permanent faculty member (one of the authors). Moreover, the faculty member has a long history of performing experiments in this particular institution and is well known for paying students to participate in experiments. Therefore, mistrust issues are expected to be minimal, if any. Subjects knew beforehand how to contact the experimenter through telephone and email and where his office is located on campus. In all, subjects provided 30 choices for the time preference task that are used to infer time preferences. In these tasks, the FED was made variable between-subjects, while the the horizon to the larger-later payoff was always fixed at 190 days.

Financial constraints precluded us from paying every single subject; hence, subjects were given a 5\% chance of receiving any money from this task and they knew this beforehand. If a subject was selected to receive money from this task, only one of their choices was selected as binding and their choice was realized. Subjects were subsequently contacted by the experimenter and were provided with details about when to receive their payment. All vouchers with the corresponding amount that they had won were delivered to subjects on the date the subject had selected for her respective choice.

Experimental instructions for this task can be found in the Electronic Supplementary Material in Section A. Figure 3 shows example screens for the time preference choice task. Because Read et al. (2005) document a date/delay effect; i.e., choices to be more patient when they are described using calendar dates than when choices are characterized in terms of time delay from the current moment, we used both dates and time delay to frame choices. Each choice always displayed a calendar to illustrate the time delay and the choices listed the delivery calendar dates along with the monetary amount. 
Table 5 Payoff table in discount rate tasks

\begin{tabular}{|c|c|c|c|c|}
\hline $\begin{array}{l}\text { Payoff alterna- } \\
\text { tive }\end{array}$ & $\begin{array}{l}\text { Payment option } \\
\text { A }\end{array}$ & $\begin{array}{l}\text { Middle payment } \\
\text { option }\end{array}$ & Payment option B & Annual interest rate \\
\hline 1 & 60 & $\mathrm{~A} \sim \mathrm{B}$ & 61.58 & 0.05 \\
\hline 2 & 60 & $\mathrm{~A} \sim \mathrm{B}$ & 63.17 & 0.10 \\
\hline 3 & 60 & $\mathrm{~A} \sim \mathrm{B}$ & 64.76 & 0.15 \\
\hline 4 & 60 & $\mathrm{~A} \sim \mathrm{B}$ & 66.35 & 0.20 \\
\hline 5 & 60 & $\mathrm{~A} \sim \mathrm{B}$ & 67.94 & 0.25 \\
\hline 6 & 60 & $\mathrm{~A} \sim \mathrm{B}$ & 69.54 & 0.30 \\
\hline 7 & 60 & $\mathrm{~A} \sim \mathrm{B}$ & 71.13 & 0.35 \\
\hline 8 & 60 & $\mathrm{~A} \sim \mathrm{B}$ & 72.73 & 0.40 \\
\hline 9 & 60 & $\mathrm{~A} \sim \mathrm{B}$ & 74.33 & 0.45 \\
\hline 10 & 60 & $\mathrm{~A} \sim \mathrm{B}$ & 75.94 & 0.50 \\
\hline 11 & 90 & $\mathrm{~A} \sim \mathrm{B}$ & 92.38 & 0.05 \\
\hline 12 & 90 & $\mathrm{~A} \sim \mathrm{B}$ & 94.76 & 0.10 \\
\hline 13 & 90 & $\mathrm{~A} \sim \mathrm{B}$ & 97.14 & 0.15 \\
\hline 14 & 90 & $\mathrm{~A} \sim \mathrm{B}$ & 99.53 & 0.20 \\
\hline 15 & 90 & $\mathrm{~A} \sim \mathrm{B}$ & 101.91 & 0.25 \\
\hline 16 & 90 & $\mathrm{~A} \sim \mathrm{B}$ & 104.31 & 0.30 \\
\hline 17 & 90 & $\mathrm{~A} \sim \mathrm{B}$ & 106.70 & 0.35 \\
\hline 18 & 90 & $\mathrm{~A} \sim \mathrm{B}$ & 109.10 & 0.40 \\
\hline 19 & 90 & $\mathrm{~A} \sim \mathrm{B}$ & 111.50 & 0.45 \\
\hline 20 & 90 & $\mathrm{~A} \sim \mathrm{B}$ & 113.90 & 0.50 \\
\hline 21 & 60 & 60.79 & 63.17 & $0.05,0.10$ \\
\hline 22 & 60 & 62.33 & 66.35 & $0.15,0.20$ \\
\hline 23 & 60 & 63.85 & 69.54 & $0.25,0.30$ \\
\hline 24 & 60 & 65.33 & 72.73 & $0.35,0.40$ \\
\hline 25 & 60 & 66.78 & 75.94 & $0.45,0.50$ \\
\hline 26 & 90 & 91.18 & 94.76 & $0.05,0.10$ \\
\hline 27 & 90 & 93.50 & 99.53 & $0.15,0.20$ \\
\hline 28 & 90 & 95.77 & 104.31 & $0.25,0.30$ \\
\hline 29 & 90 & 98.00 & 109.10 & $0.35,0.40$ \\
\hline 30 & 90 & 100.17 & 113.90 & $0.45,0.50$ \\
\hline
\end{tabular}

The sooner option (option A) was delivered on March 21 in the 2019 wave, March 19 in the 2020A wave and June 1 on the $2020 \mathrm{~B}$ wave. The later option (option B) was delivered 190 days later. The middle option for the payoff alternatives 1 to 20 was an option of stating indifference between payment option A and payment option B. The middle option monetary amount for the payoff alternatives 21 to 30 , was delivered 95 days later than option A. In choices 21 to 30, the middle option is compounded with the smaller interest rate of the two rates listed in the last column and the later option is compounded with the largest interest rate of the two rates listed in the last column

\subsection{Theory and econometrics of risk and time preferences}

We use standard structural models to estimate risk and time preferences parameters. Section D in the Electronic Supplementary Material presents many of the details of 
(a) Two options

\section{Choice 4}

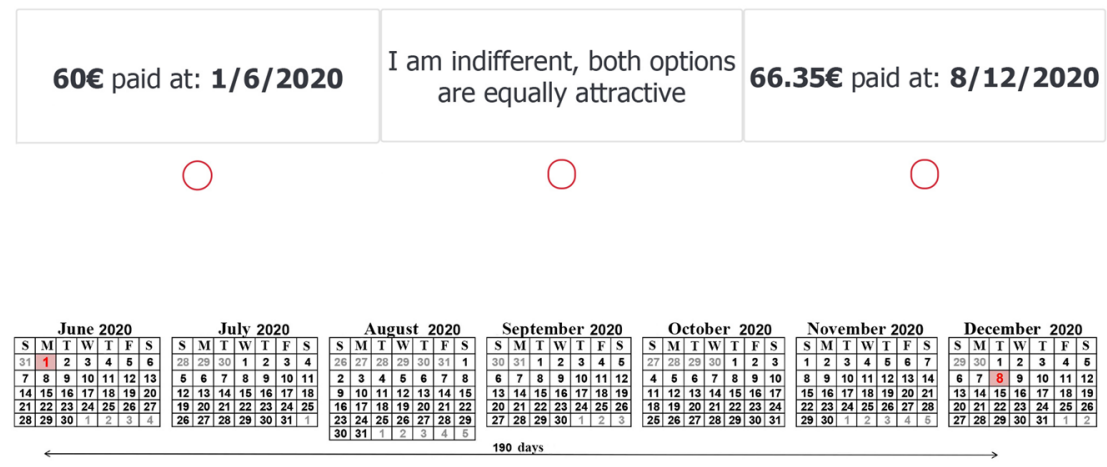

(b) Three options

\section{Choice 24}

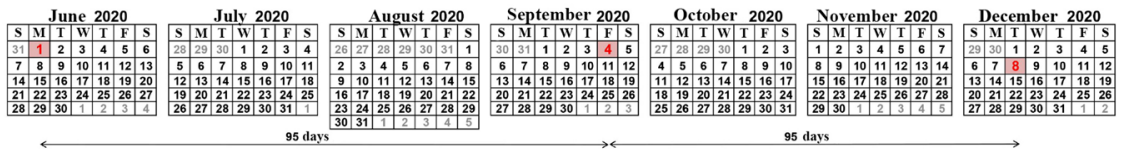

Fig. 3 Example screen for time dated monetary choices

our approach that is standard and well documented by now (Andersen et al. 2008a, 2013, 2014), so here we only write out the essentials.

We let the utility function be the constant relative risk aversion (CRRA) specification, $U(M)=\frac{M^{1-r}}{1-r}$, where $r$ is the relative risk aversion (RRA) coefficient, $r=0$ denotes risk neutral behavior, $r>0$ denotes risk averse behavior and $r<0$ denotes risk loving behavior. We can either assume Expected Utility Theory (EUT): $E U_{i}=\sum_{j=1,2} p_{i}\left(M_{j}\right) U\left(M_{j}\right)$, where $p\left(M_{j}\right)$ are the probabilities for each outcome $M_{j}$ that are induced by the experimenter (shown in Tables 3 and 4) or Rank Dependent Utility (RDU) (Quiggin 1982): $R D U_{i}=\sum_{j=1,2} w_{i}\left[p\left(M_{j}\right)\right] U\left(M_{j}\right)=\sum_{j=1,2} w_{i j} U\left(M_{j}\right)$ where $w_{i 2}=w_{i}\left(p_{2}+p_{1}\right)-w_{i}\left(p_{1}\right)=1-w_{i}\left(p_{1}\right)$ and $w_{i 1}=w_{i}\left(p_{1}\right)$ with outcomes ranked from worst to best and $w(\cdot)$ is the probability weighting function. ${ }^{15}$ For the

\footnotetext{
15 As in most experiments of choice under risk, our experiment involved multiple choices over lotteries for which subjects where randomly paid for one of these choices. This payoff mechanism, known as the
} 
case of RDU we use Prelec's (1998) two parameter probability weighting function: $w(p)=\exp \left(-\beta_{r}(-\ln p)^{a_{r}}\right)$ where $a_{r}>0,0<p<1, \beta_{r}>0$ (if $a_{r}=1$ it collapses to the power function $w(p)=p^{\beta_{r}}$; if $a_{r}=\beta_{r}=1$ it collapses to $w(p)=p$ ).

With respect to time preferences, we can write the indifference between two income options $M_{t}$ and $M_{t+\tau}$ as: $U\left(M_{t}\right)=\frac{1}{(1+\delta)^{\tau}} U\left(M_{t+\tau}\right)$ where $D^{E}(\tau)=\frac{1}{(1+\delta)^{\tau}}$ is the discount factor under exponential discounting for $\tau \geq 0$ and the discount rate is $d^{E}(\tau)=\delta$. As an alternative, we use the hyperbolic specification due to Mazur (1984) which specifies the discount factor as $D^{H}(\tau)=\frac{1}{(1+K \tau)}$ for some parameter $K>0$ and discount rates $d^{H}(\tau)=(1+K \tau)^{(1 / \tau)}-1 .^{16}$

The joint likelihood of the risk aversion and discount rate responses can then be written as:

$$
\ln L(r, T, \mu, v ; y, \mathbf{X})=\ln L^{R A}+\ln L^{D}
$$

In Eq. 1, it is $\ln L^{R A}(r, \mu ; y, \mathbf{X})=\sum_{i=1}^{N}\left[\left(\ln \left(P r_{B}^{R A}\right) \mid y_{i}=1\right)+\left(\ln \left(1-P r_{B}^{R A}\right) \mid y_{i}=0\right)+\left(\frac{1}{2} \ln \left(P r_{B}^{R A}\right)+\frac{1}{2} \ln \left(1-P r_{B}^{R A}\right) \mid y_{i}=-1\right)\right]$, where $y_{i}=1,0$ denotes the choice of lottery $\mathrm{B}$ or $\mathrm{A}$ in the $i$ th risk preference task, respectively, and $y_{i}=-1$ denotes the choice of indifference. Moreover, it is $\ln L^{D}(T, v ; y, \mathbf{X})=\sum_{i=1}^{N}\left[\left(\ln \left(\operatorname{Pr}_{B}^{D}\right) \mid y_{i}=1\right)+\left(\ln \left(\operatorname{Pr}_{A}^{D}\right) \mid y_{i}=0\right)+\left(\frac{1}{2} \ln \left(\operatorname{Pr}_{A}^{D}\right)+\frac{1}{2} \ln \left(\operatorname{Pr}_{B}^{D}\right) \mid y_{i}=-1\right)+\left(\ln \left(\operatorname{Pr}_{C}^{D}\right) \mid y_{i}=2\right)\right] \quad$ where $y_{i}=1,0$ denotes the choice of option B (the later option) or A (the sooner option) in the $i$ th time preference task, respectively, $y_{i}=-1$ denotes the choice of indifference and $y_{i}=2$ denotes the choice of the middle option C. $X$ is a vector of variables that are assumed to affect the estimated parameters. $T$ is either $\delta$ under exponential discounting or $K$ under the hyperbolic specification.

Equation (1) is maximized using standard numerical methods by taking into account the multiple responses given by the same subject and allows for correlation between responses by clustering the standard errors (StataCorp 2013, pp. 312).

Footnote 15 (continued)

Random Lottery Incentive Mechanism (RLIM), is incentive compatible if and only if the Independence Axiom holds (Holt 1986). Given that RDU does not include the independence axiom, then RLIM is inappropriate for non-EUT theories on theoretical grounds. The use of the RLIM under non-EUT specifications either invokes the assumption of the isolation effect; i.e., that a subject views each choice in an experiment as independent of other choices in the experiment or assumes two independence axioms as in Harrison and Swarthout (2014): one axiom that applies to the evaluation of a given prospect which is assumed to be violated by RDU, and another axiom that applies to the evaluation of the experimental payment protocol. Only the validity of the latter axiom is required to ensure incentive compatibility of the RLIM.

16 The hyperbolic specification does not nest exponential discounting in the way RDU nests EUT and, therefore, other alternatives have been proposed. A two parameter specification based on the Weibull distribution from statistics, defines the discount factor as $D^{W}(\tau)=\exp \left(-r_{d} t^{\left(1 / s_{d}\right)}\right)$ for $r_{d}, s_{d}>0$. For $s_{d}=1$ this collapses to the exponential discounting specification. Unfortunately, when we tried to fit this specification with our data, we run into severe numerical optimization problems and none of our efforts was fruitful. 


\section{Results}

In order to explore the effect of the pandemic on risk and time preferences, we modeled the structural parameters as a function of either (a) wave dummies defined as dummies for the waves 2019 (pre-pandemic wave), 2020A and 2020B (see also Table 2) or (b) event dummies defined as key events that occurred in the timeline of the pandemic in the country. These events are: (i) first reported case in the country (February 26; overlaps with the 2020A wave), (ii) first reported death in the country (March 12; overlaps with the 2020A wave), (iii) onset of curfew when all nonessential transport and movements across the country were banned (March 23; coincides with the beginning of the 2020B wave), (iv) announcement of a plan for the gradual lifting of the restrictive measures and the restart of business activity (April 27; overlaps with the 2020B wave) and curfew relaxation and business re-openning (May 4; overlaps with the $2020 \mathrm{~B}$ wave) ${ }^{17}$ Figure $1 \mathrm{~b}$ shows a timeline of these events as well. In what follows, we present both EUT and RDU models (with Prelec's (1998) two parameter probability weighting function) with an exponential and hyperbolic discount function. ${ }^{18}$

Table 6 shows the estimates of the structural parameters for EUT and RDU under exponential discounting, that are modeled as a function of two sets of dummy variables. Table 7 shows the respective estimates under hyperbolic discounting. Models (1) and (2) in Tables 6 and 7 use the wave dummies while models (3) and (4) use the event dummies. As evident, none of the wave or event dummies are statistically significant at the 5\% level, indicating remarkable stability of estimated risk and time preference parameters across time. Joint significance tests that all wave dummies are equal to zero fail to reject the null across all models of the tables (results of the Wald tests are shown in the tables as well).

The estimated parameters also allow us to test the RDU model versus the EUT by testing whether $a_{r}=\beta_{r}=1$ in the probability weighting function $w(p)=\exp \left(-\beta_{r}(-\ln p)^{a_{r}}\right)$. Table 6 shows that under exponential discounting, a joint significance test that $a_{r}=\beta_{r}=1$ rejects the null in favor of RDU while Table 7 shows that under hyperbolic discounting, we fail to reject the null in favor of EUT. ${ }^{19}$

Because coefficient estimates of the discount factor $K$ (shown in Table 7) cannot be interpreted as is, we also calculated the discount rate $d^{H}(\tau)=(1+K \tau)^{(1 / \tau)}-1$ for each of the estimated models of Table 7. Implied annualized discount rates are in the range of $23 \%$ for a period of two weeks and go down to around $22 \%$ for a

\footnotetext{
${ }^{17}$ Because the time between announcement of relaxation of the restrictive measures and the actual relaxation was very short, we merged these two key events in one.

${ }^{18} \mathrm{We}$ also constructed simple measures of the number of safe choices (for risk preferences) and sooner choices (for time preferences) and did Kruskal-Wallis tests by waves and events. All tests fail to reject the null at conventional statistical significance levels (for the number of safe choices, $p$-values are 0.274 and 0.190 for the waves and events dummies, respectively; for the number of sooner choices, $p$-values are 0.476 and 0.827 for the waves and events dummies, respectively).

${ }^{19}$ Since none of the covariates of $a_{r}$ and $\beta_{r}$ in Tables 6 and 7 are statistically significant, to simplify the Wald test we jointly tested whether the constants are equal to one and the coefficients of all other covariates are equal to zero.
} 
delay period of 6 months. Given that confidence intervals for the different time horizons overlap, there is no evidence of significantly declining discount rates, a finding which is consistent with Andersen et al. (2014). Estimated discount rates are much higher than those reported in Andersen et al. (2014) for a representative sample of Danes (around 10\% under exponential discounting and between 13.7\% and 11.3\% according to a Weibull specification).

The results are similar if we constrain the sample to only those for which we have their data for at least two waves (see Tables A4 and A5 in the Electronic Supplementary Material) or to only those for which we have their data for all three waves (see Tables A6 and A7 in the Electronic Supplementary Material) or to only those that the electronic payment transaction went through after the end of the experiment (see Tables A8 and A9 in the Electronic Supplementary Material). Every single joint significance test reported in these tables regarding the wave dummies or event dummies being equal to zero, fails to reject the null.

In order to account for some observed heterogeneity, we can augment the base models by including available demographics as well as variables related to the perception of the pandemic or attitudes, and coping with it. ${ }^{20} \mathrm{We}$ first constructed a measure of the number of cases at the level of administrative regions of the country, adjusted for the population size (i.e., number of cases was divided by the population size of the respective region). We achieved this by matching IP (Internet Protocol) address geolocation data with the number of recorded cases in the respective administrative region the day each subject responded. ${ }^{21}$ Naturally, this measure takes a value of zero for dates before the onset of the pandemic. Table A11 in the Electronic Supplementary Material shows that the vast majority of responses (>90\%) originated from the cities of Athens/Piraeus and Thessaloniki which account for roughly $40 \%$ of the population in the country.

Tables 8 and 9 show similar models to what we estimated previously, augmented with gender, age, household size, income, smoking status and number of cases in the administrative region of the respondent. Like before, none of the wave or event dummies is statistically significant and the joint significance tests that all wave or event dummies are zero fail to reject the null. ${ }^{22}$ These results along with previous results

\footnotetext{
${ }^{20}$ The downside is that we lose a few observations by doing so and that convergence problems arise.

${ }^{21}$ We queried the recorded IP addresses collected by Qualtrics with http://ip-api.com which is an application programming interface that allows to query IP addresses and returns back location data at the level of region/city in the country. IP addresses that pointed to locations outside of the country were dropped (17 responses). The number of cases per day and per region is maintained and curated by iMEdD's (Incubator for Media Education and Development) content production division. iMEdD is a non profit organization founded with a donation of Stavros Niarchos Foundation and has a mission to support and promote the transparency, credibility and independence in journalism on the grounds of securing meritocracy and excellence in the field. The data can be found in iMEdD's GitHub repository: https://github. com/iMEdD-Lab/open-data. We also constructed a measure of number of deaths but this is highly correlated with number of cases $(\rho=0.991)$, so we only used the latter in our models to avoid high multicollinearity.

${ }^{22}$ Moreover, to test whether estimating the models separately by wave makes a difference in the estimated coefficients (i.e., that estimated coefficients are different between waves for the covariates shown in Tables 8 and 9), we performed Chow tests. We fail to reject the null of no difference between waves for the coefficients of the independent variables of models (1) and (2) of Tables 8 and 9 (test statistics are $\chi^{2}=4.99(p$-value $=0.986), \chi^{2}=5.33(p$-value $=0.981), \chi^{2}=18.27(p$-value $=0.999), \chi^{2}=20.16$ $(p$-value $=0.998)$, respectively $)$.
} 
Table 6 Structural estimates with exponential discounting

\begin{tabular}{|c|c|c|c|c|c|c|c|c|}
\hline & \multirow{2}{*}{$\frac{\text { EUT }}{(1)}$} & & \multicolumn{2}{|l|}{ RDU } & \multicolumn{2}{|l|}{ EUT } & \multicolumn{2}{|l|}{ RDU } \\
\hline & & & (2) & & (3) & & (4) & \\
\hline \multicolumn{9}{|l|}{$r$} \\
\hline Constant & $0.547 * * *$ & $(0.027)$ & $0.656^{* * *} *$ & $(0.056)$ & $0.547 * * *$ & $(0.027)$ & $0.666 * * *$ & $(0.056)$ \\
\hline 2020A wave & 0.032 & $(0.039)$ & -0.030 & $(0.072)$ & & & & \\
\hline 2020B wave & -0.024 & $(0.039)$ & 0.008 & $(0.058)$ & & & & \\
\hline \multicolumn{9}{|l|}{2020 events: } \\
\hline Before first case & & & & & 0.052 & $(0.046)$ & -0.062 & $(0.085)$ \\
\hline $\begin{array}{l}\text { Before first } \\
\text { death }\end{array}$ & & & & & 0.024 & $(0.055)$ & 0.043 & (0.094) \\
\hline Before curfew & & & & & -0.058 & $(0.093)$ & -0.072 & $(0.223)$ \\
\hline Curfew starts & & & & & 0.018 & $(0.048)$ & 0.043 & $(0.066)$ \\
\hline $\begin{array}{l}\text { Curfew } \\
\text { announced } \\
\text { relaxation }\end{array}$ & & & & & -0.070 & $(0.049)$ & -0.038 & $(0.076)$ \\
\hline \multicolumn{9}{|l|}{$a_{r}$} \\
\hline Constant & & & $0.855^{* * *}$ & $(0.057)$ & & & $0.849 * * *$ & $(0.056)$ \\
\hline 2020A wave & & & -0.015 & $(0.077)$ & & & & \\
\hline 2020B wave & & & -0.033 & $(0.077)$ & & & & \\
\hline \multicolumn{9}{|l|}{2020 events: } \\
\hline Before first case & & & & & & & 0.031 & $(0.094)$ \\
\hline $\begin{array}{l}\text { Before first } \\
\text { death }\end{array}$ & & & & & & & -0.040 & $(0.100)$ \\
\hline Before curfew & & & & & & & -0.129 & $(0.164)$ \\
\hline Curfew starts & & & & & & & -0.077 & $(0.087)$ \\
\hline $\begin{array}{l}\text { Curfew } \\
\text { announced } \\
\text { relaxation }\end{array}$ & & & & & & & 0.017 & $(0.102)$ \\
\hline \multicolumn{9}{|l|}{$\beta_{r}$} \\
\hline Constant & & & $0.798 * * *$ & $(0.071)$ & & & $0.784 * * *$ & $(0.069)$ \\
\hline 2020A wave & & & 0.068 & $(0.085)$ & & & & \\
\hline 2020B wave & & & -0.046 & $(0.067)$ & & & & \\
\hline \multicolumn{9}{|l|}{2020 events: } \\
\hline Before first case & & & & & & & 0.151 & $(0.100)$ \\
\hline $\begin{array}{l}\text { Before first } \\
\text { death }\end{array}$ & & & & & & & -0.033 & (0.104) \\
\hline Before curfew & & & & & & & -0.020 & $(0.233)$ \\
\hline Curfew starts & & & & & & & -0.059 & $(0.079)$ \\
\hline $\begin{array}{l}\text { Curfew } \\
\text { announced } \\
\text { relaxation }\end{array}$ & & & & & & & -0.023 & $(0.082)$ \\
\hline \multicolumn{9}{|l|}{$\delta$} \\
\hline Constant & $0.212 * * *$ & $(0.016)$ & $0.158^{* * * *}$ & $(0.027)$ & $0.212 * * *$ & $(0.016)$ & $0.153 * * *$ & $(0.026)$ \\
\hline 2020A wave & -0.016 & $(0.022)$ & 0.016 & $(0.037)$ & & & & \\
\hline
\end{tabular}


Table 6 (continued)

\begin{tabular}{|c|c|c|c|c|c|c|c|c|}
\hline \multirow{3}{*}{ 2020B wave } & \multirow{2}{*}{\multicolumn{2}{|c|}{$\frac{\text { EUT }}{(1)}$}} & \multirow{2}{*}{\multicolumn{2}{|c|}{$\frac{\mathrm{RDU}}{(2)}$}} & \multirow{2}{*}{\multicolumn{2}{|c|}{$\frac{\text { EUT }}{(3)}$}} & \multirow{2}{*}{\multicolumn{2}{|c|}{$\frac{\mathrm{RDU}}{\mathrm{(4)}}$}} \\
\hline & & & & & & & & \\
\hline & \multirow[t]{7}{*}{0.030} & \multirow[t]{7}{*}{$(0.024)$} & \multirow[t]{7}{*}{0.007} & \multirow[t]{7}{*}{$(0.030)$} & & & & \\
\hline 2020 events: & & & & & & & & \\
\hline Before first case & & & & & -0.030 & $(0.025)$ & 0.030 & $(0.042)$ \\
\hline $\begin{array}{l}\text { Before first } \\
\text { death }\end{array}$ & & & & & -0.008 & $(0.031)$ & -0.018 & $(0.048)$ \\
\hline Before curfew & & & & & 0.034 & $(0.058)$ & 0.039 & $(0.120)$ \\
\hline Curfew starts & & & & & 0.007 & $(0.029)$ & -0.012 & $(0.034)$ \\
\hline $\begin{array}{l}\text { Curfew } \\
\text { announced } \\
\text { relaxation }\end{array}$ & & & & & $0.058 *$ & $(0.031)$ & 0.032 & $(0.041)$ \\
\hline$\mu$ & $0.131 * * *$ & $(0.003)$ & $0.116^{* * * *}$ & $(0.006)$ & $0.131 * * *$ & $(0.003)$ & $0.115 * * *$ & $(0.005)$ \\
\hline$v$ & $0.068 * * *$ & $(0.002)$ & $0.071 * * *$ & $(0.003)$ & $0.068 * * *$ & $(0.002)$ & $0.071 * * *$ & $(0.003)$ \\
\hline \multicolumn{9}{|c|}{ Wald tests (joint significance): } \\
\hline $\begin{array}{l}\text { Wave/event } \\
\text { dummies }=0\end{array}$ & $\chi^{2}=3.21$ & $(0.524)$ & $\chi^{2}=1.78$ & $(0.987)$ & $\chi^{2}=9.32$ & $(0.502)$ & $\chi^{2}=7.74$ & $(0.993)$ \\
\hline$a_{r}=\beta_{r}=1$ & & & $\chi^{2}=15.99$ & $(0.014)$ & & & $\chi^{2}=21.66$ & $(0.041)$ \\
\hline$N$ & \multicolumn{2}{|l|}{47800} & \multicolumn{2}{|l|}{47800} & \multicolumn{2}{|l|}{47800} & \multicolumn{2}{|c|}{47800} \\
\hline Log-likelihood & \multicolumn{2}{|l|}{-28472.86} & \multicolumn{2}{|l|}{-28455.17} & \multicolumn{2}{|l|}{-28461.96} & \multicolumn{2}{|l|}{-28439.62} \\
\hline
\end{tabular}

Standard errors in parentheses for coefficient estimates. $p$-values in parenthesis for Wald tests. $* p<0.1$, $* * p<0.05 * * * p<0.01$. For all models, the base category is the 2019 wave which is captured by the constant for each parameter. $r$ is the CRRA coefficient; $a_{r}, \beta_{r}$ are the parameters of the Prelec probability weighting function; $\delta$ is the discount rate 
Table 7 Structural estimates with hyperbolic discounting

\begin{tabular}{|c|c|c|c|c|c|c|c|c|}
\hline & EUT & & RDU & & EUT & & RDU & \\
\hline & (1) & & (2) & & (3) & & (4) & \\
\hline$r$ & & & & & & & & \\
\hline Constant & $0.542 * * *$ & $(0.026)$ & $0.538 * * *$ & $(0.053)$ & $0.542 * * *$ & $(0.026)$ & $0.543 * * *$ & $(0.052)$ \\
\hline 2020A wave & 0.032 & $(0.038)$ & -0.066 & $(0.085)$ & & & & \\
\hline 2020B wave & -0.023 & $(0.039)$ & 0.014 & $(0.064)$ & & & & \\
\hline 2020 events: & & & & & & & & \\
\hline Before first case & & & & & 0.052 & $(0.045)$ & -0.087 & $(0.095)$ \\
\hline Before first death & & & & & 0.024 & $(0.055)$ & -0.002 & $(0.122)$ \\
\hline Before curfew & & & & & -0.056 & $(0.093)$ & -0.106 & $(0.260)$ \\
\hline Curfew starts & & & & & 0.016 & $(0.048)$ & 0.035 & $(0.075)$ \\
\hline $\begin{array}{l}\text { Curfew } \\
\text { announced } \\
\text { relaxation }\end{array}$ & & & & & -0.069 & $(0.049)$ & -0.025 & $(0.083)$ \\
\hline$a_{r}$ & & & & & & & & \\
\hline Constant & & & $0.885^{* * *}$ & $(0.060)$ & & & $0.881 * * *$ & $(0.059)$ \\
\hline 2020A wave & & & -0.023 & $(0.082)$ & & & & \\
\hline 2020B wave & & & -0.028 & $(0.083)$ & & & & \\
\hline 2020 events: & & & & & & & & \\
\hline Before first case & & & & & & & 0.025 & $(0.099)$ \\
\hline Before first death & & & & & & & -0.056 & $(0.105)$ \\
\hline Before curfew & & & & & & & -0.129 & $(0.182)$ \\
\hline Curfew starts & & & & & & & -0.082 & $(0.094)$ \\
\hline $\begin{array}{l}\text { Curfew } \\
\text { announced } \\
\text { relaxation }\end{array}$ & & & & & & & 0.034 & $(0.111)$ \\
\hline$\beta_{r}$ & & & & & & & & \\
\hline Constant & & & $0.949 * * *$ & $(0.076)$ & & & $0.941 * * *$ & $(0.075)$ \\
\hline 2020A wave & & & 0.123 & $(0.113)$ & & & & \\
\hline 2020B wave & & & -0.059 & $(0.084)$ & & & & \\
\hline 2020 events: & & & & & & & & \\
\hline Before first case & & & & & & & $0.210^{*}$ & $(0.127)$ \\
\hline Before first death & & & & & & & 0.007 & $(0.155)$ \\
\hline Before curfew & & & & & & & 0.008 & $(0.321)$ \\
\hline Curfew starts & & & & & & & -0.061 & $(0.100)$ \\
\hline $\begin{array}{l}\text { Curfew } \\
\text { announced } \\
\text { relaxation }\end{array}$ & & & & & & & -0.039 & $(0.103)$ \\
\hline$K$ & & & & & & & & \\
\hline Constant & $0.208 * * *$ & $(0.015)$ & $0.209 * * *$ & $(0.025)$ & $0.208 * * *$ & $(0.015)$ & $0.207 * * *$ & $(0.025)$ \\
\hline 2020A wave & -0.016 & $(0.021)$ & 0.035 & $(0.044)$ & & & & \\
\hline 2020B wave & 0.030 & $(0.023)$ & 0.009 & $(0.034)$ & & & & \\
\hline 2020 events: & & & & & & & & \\
\hline Before first case & & & & & -0.028 & $(0.024)$ & 0.045 & $(0.047)$ \\
\hline
\end{tabular}


Table 7 (continued)

\begin{tabular}{|c|c|c|c|c|c|c|c|c|}
\hline & \multicolumn{2}{|l|}{ EUT } & \multicolumn{2}{|l|}{ RDU } & \multicolumn{2}{|l|}{ EUT } & \multicolumn{2}{|l|}{ RDU } \\
\hline & (1) & & (2) & & (3) & & (4) & \\
\hline Before first death & & & & & -0.008 & $(0.030)$ & 0.005 & $(0.063)$ \\
\hline Before curfew & & & & & 0.027 & $(0.053)$ & 0.053 & $(0.137)$ \\
\hline Curfew starts & & & & & 0.011 & $(0.029)$ & -0.0002 & $(0.040)$ \\
\hline $\begin{array}{l}\text { Curfew } \\
\text { announced } \\
\text { relaxation }\end{array}$ & & & & & $0.052 *$ & $(0.029)$ & 0.027 & $(0.044)$ \\
\hline$\mu$ & $0.131 * * *$ & $(0.003)$ & $0.126 * * *$ & $(0.005)$ & $0.131 * * *$ & $(0.003)$ & $0.125 * * *$ & $(0.005)$ \\
\hline$v$ & $0.067 * * *$ & $(0.002)$ & $0.066 * * *$ & $(0.003)$ & $0.067 * * *$ & $(0.002)$ & $0.067 * * *$ & $(0.003)$ \\
\hline \multicolumn{9}{|c|}{ Wald tests (joint significance): } \\
\hline $\begin{array}{l}\text { Wave/event } \\
\text { dummies }=0\end{array}$ & $\chi^{2}=3.35$ & $(0.502)$ & $\chi^{2}=3.24$ & $(0.918)$ & $\chi^{2}=8.97$ & $(0.535)$ & $\chi^{2}=7.69$ & $(0.994)$ \\
\hline$a_{r}=\beta_{r}=1$ & & & $\chi^{2}=5.98$ & $(0.425)$ & & & $\chi^{2}=9.62$ & $(0.649)$ \\
\hline$N$ & 47800 & & 47800 & & 47800 & & 47800 & \\
\hline Log-likelihood & -28423.46 & & -28409.29 & & -28412.41 & & -28394.83 & \\
\hline
\end{tabular}

Standard errors in parentheses for coefficient estimates. $p$-values in parenthesis for Wald tests. ${ }^{*} p<0.1$, $* * p<0.05 * * * p<0.01$. For all models, the base category is the 2019 wave which is captured by the constant for each parameter. $r$ is the CRRA coefficient; $a_{r}, \beta_{r}$ are the parameters of the Prelec probability weighting function; $K$ is the parameter of the hyperbolic function

from Tables 6 and 7 , allow us to claim both conditional and unconditional stability of risk preferences, as per our earlier discussion of this distinction.

Table 10 shows structural parameter estimates when augmenting the models to include a set of variables from questions that where included in the last wave, in order to capture attitudes and behavior with respect to the pandemic (naturally, the sample is constrained to the $2020 \mathrm{~B}$ wave). ${ }^{23}$

\footnotetext{
23 The set of variables includes: (a) dummies about perception of how effective social distancing is with possible answers being (i) very inefficient or inefficient, (ii) neither inefficient, nor efficient, (iii) efficient (iv) very efficient, (b) a dummy about whether the respondent has family members or others in their inner circle considered a high risk group, (c) a composite score variable capturing whether respondents are stressed about the pandemic situation. This composite score variable was constructed as the sum of five variables that respondents answered on a five Likert scale ranging from 'highly disagree' to 'highly agree': (i) I'm nervous/stressed (ii) I'm calm/relaxed (reverse coded) (iii) I worry about my health (iv) I worry about the health of members of my family (v) I feel stressed when I have to leave home, (d) a composite variable capturing whether respondents' tendency to attribute the virus or the pandemic in conspiracy theories or misconceptions about the virus. This composite score variable was constructed as the sum of five variables that respondents answered on a five Likert scale ranging from 'very unlikely' to 'very likely': (i) Coronavirus was made in a lab in China, got out of control and transmitted to the population (ii) Coronavirus was made in a US lab and US soldiers then infected the population in China (iii) Coronavirus is a zoonosis that spread from animals to humans (reverse coded) (iv) Coronavirus is no more dangerous than common flu (v) Coronavirus was invented as a pretense for limiting personal liberties. The RDU models in Table 10 would not converge for the full set of variables for $K$ that are included for the other parameters $\left(r, a_{r}, \beta_{r}\right)$, so we report the largest set of coefficient estimates that we could get results for. Table A10 in the Electronic Supplementary Material reports results for the RDU models using a balanced set of variables across all parameters $\left(K, r, a_{r}, \beta_{r}\right)$.
} 
Table 8 Structural estimates with exponential discounting and additional controls

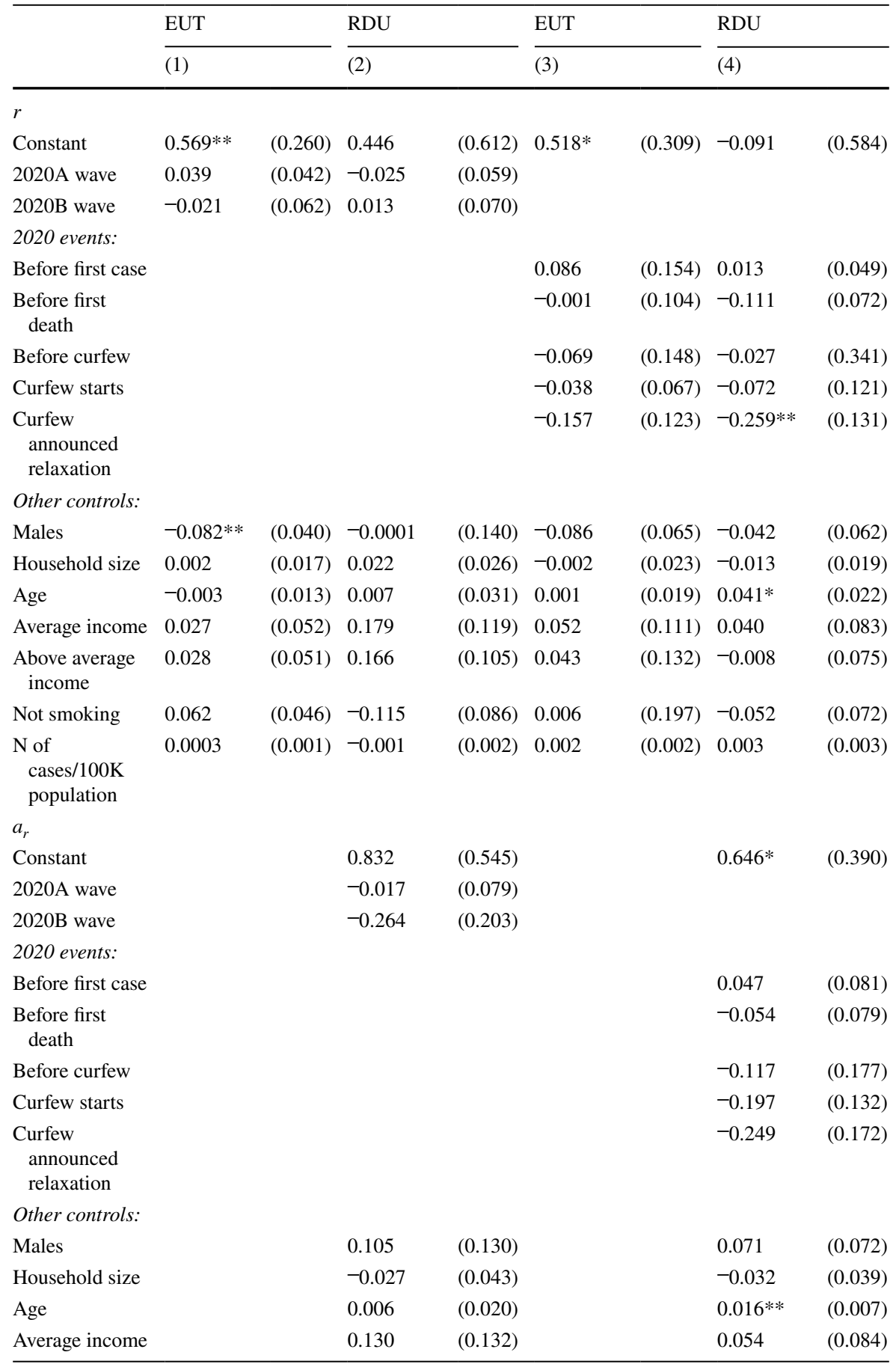


Table 8 (continued)

\begin{tabular}{|c|c|c|c|c|c|c|c|c|}
\hline & \multirow{2}{*}{$\frac{\text { EUT }}{(1)}$} & & \multirow{2}{*}{\multicolumn{2}{|c|}{$\frac{\mathrm{RDU}}{(2)}$}} & \multirow{2}{*}{\multicolumn{2}{|c|}{$\frac{\text { EUT }}{(3)}$}} & \multirow{2}{*}{\multicolumn{2}{|c|}{$\frac{\mathrm{RDU}}{(4)}$}} \\
\hline & & & & & & & & \\
\hline $\begin{array}{l}\text { Above average } \\
\text { income }\end{array}$ & & & 0.032 & $(0.093)$ & & & -0.038 & $(0.066)$ \\
\hline Not smoking & & & -0.116 & $(0.121)$ & & & -0.067 & $(0.079)$ \\
\hline $\begin{array}{l}\mathrm{N} \text { of } \\
\text { cases/100K } \\
\text { population }\end{array}$ & & & 0.008 & $(0.007)$ & & & 0.007 & $(0.005)$ \\
\hline \multicolumn{9}{|l|}{$\beta_{r}$} \\
\hline Constant & & & 1.269 & $(0.925)$ & & & 2.245 & $(1.626)$ \\
\hline 2020A wave & & & 0.073 & $(0.108)$ & & & & \\
\hline 2020B wave & & & -0.230 & $(0.243)$ & & & & \\
\hline \multicolumn{9}{|l|}{2020 events: } \\
\hline Before first case & & & & & & & 0.188 & $(0.284)$ \\
\hline $\begin{array}{l}\text { Before first } \\
\text { death }\end{array}$ & & & & & & & 0.284 & $(0.418)$ \\
\hline Before curfew & & & & & & & -0.262 & $(0.930)$ \\
\hline Curfew starts & & & & & & & -0.186 & $(0.321)$ \\
\hline $\begin{array}{l}\text { Curfew } \\
\text { announced } \\
\text { relaxation }\end{array}$ & & & & & & & -0.108 & $(0.420)$ \\
\hline \multicolumn{9}{|l|}{ Other controls: } \\
\hline Males & & & -0.061 & $(0.166)$ & & & -0.011 & $(0.203)$ \\
\hline Household size & & & -0.048 & $(0.044)$ & & & 0.002 & $(0.071)$ \\
\hline Age & & & -0.025 & $(0.061)$ & & & -0.122 & $(0.146)$ \\
\hline Average income & & & -0.114 & $(0.225)$ & & & 0.162 & $(0.277)$ \\
\hline $\begin{array}{l}\text { Above average } \\
\text { income }\end{array}$ & & & -0.191 & $(0.164)$ & & & 0.050 & $(0.231)$ \\
\hline Not smoking & & & 0.270 & $(0.232)$ & & & 0.308 & $(0.241)$ \\
\hline $\begin{array}{l}\mathrm{N} \text { of } \\
\text { cases/100K } \\
\text { population }\end{array}$ & & & 0.006 & $(0.007)$ & & & 0.005 & $(0.009)$ \\
\hline \multicolumn{9}{|l|}{$\delta$} \\
\hline Constant & 0.185 & $(0.127)$ & 0.316 & $(0.839)$ & 0.214 & $(0.181)$ & 2.474 & $(5.297)$ \\
\hline 2020A wave & -0.018 & $(0.024)$ & 0.037 & $(0.064)$ & & & & \\
\hline 2020B wave & -0.005 & $(0.031)$ & -0.041 & $(0.185)$ & & & & \\
\hline \multicolumn{9}{|l|}{2020 events: } \\
\hline Before first case & & & & & -0.048 & $(0.102)$ & -0.182 & $(0.460)$ \\
\hline $\begin{array}{l}\text { Before first } \\
\text { death }\end{array}$ & & & & & 0.006 & $(0.061)$ & 1.194 & $(2.979)$ \\
\hline Before curfew & & & & & 0.033 & $(0.102)$ & 0.257 & (3.317) \\
\hline Curfew starts & & & & & -0.001 & $(0.039)$ & 0.295 & (1.706) \\
\hline $\begin{array}{l}\text { Curfew } \\
\text { announced } \\
\text { relaxation }\end{array}$ & & & & & 0.037 & $(0.091)$ & 2.378 & (6.063) \\
\hline
\end{tabular}


Table 8 (continued)

\begin{tabular}{|c|c|c|c|c|c|c|c|c|}
\hline & \multirow{2}{*}{\multicolumn{2}{|c|}{$\frac{\text { EUT }}{(1)}$}} & \multirow{2}{*}{\multicolumn{2}{|c|}{$\frac{\mathrm{RDU}}{(2)}$}} & \multirow{2}{*}{\multicolumn{2}{|c|}{$\frac{\text { EUT }}{(3)}$}} & \multirow{2}{*}{\multicolumn{2}{|c|}{$\frac{\mathrm{RDU}}{(4)}$}} \\
\hline & & & & & & & & \\
\hline \multicolumn{9}{|l|}{ Other controls: } \\
\hline Males & 0.041 & $(0.040)$ & -0.004 & $(0.185)$ & 0.050 & $(0.074)$ & 0.422 & $(0.969)$ \\
\hline Household size & -0.010 & $(0.010)$ & -0.039 & $(0.079)$ & -0.009 & $(0.012)$ & 0.027 & $(0.181)$ \\
\hline Age & 0.004 & $(0.004)$ & -0.007 & $(0.060)$ & 0.001 & $(0.010)$ & -0.341 & $(0.902)$ \\
\hline Average income & -0.002 & $(0.026)$ & -0.142 & $(0.442)$ & -0.015 & $(0.063)$ & -0.273 & $(1.231)$ \\
\hline $\begin{array}{l}\text { Above average } \\
\text { income }\end{array}$ & -0.004 & $(0.024)$ & -0.132 & $(0.315)$ & -0.013 & $(0.073)$ & 0.172 & $(0.737)$ \\
\hline Not smoking & -0.026 & $(0.026)$ & 0.235 & $(0.551)$ & -0.003 & $(0.106)$ & 0.654 & $(0.778)$ \\
\hline $\begin{array}{l}\mathrm{N} \text { of } \\
\text { cases/100K } \\
\text { population }\end{array}$ & 0.001 & $(0.001)$ & 0.003 & $(0.009)$ & 0.0003 & $(0.001)$ & -0.010 & $(0.038)$ \\
\hline$\mu$ & $0.130 * * *$ & $(0.003)$ & $0.110 * * *$ & $(0.009)$ & $0.130 * * *$ & $(0.004)$ & $0.113 * * *$ & $(0.007)$ \\
\hline$v$ & $0.068 * * *$ & $(0.002)$ & $0.073 * * *$ & $(0.004)$ & $0.067 * * *$ & $(0.002)$ & $0.072 * * *$ & $(0.004)$ \\
\hline \multicolumn{9}{|c|}{ Wald tests (joint significance): } \\
\hline $\begin{array}{l}\text { Wave/event } \\
\text { dummies }=0\end{array}$ & $\chi^{2}=1.54$ & $(0.820)$ & $\chi^{2}=3.69$ & $(0.884)$ & $\chi^{2}=2.99$ & $(0.982)$ & $\chi^{2}=14.17$ & $(0.822)$ \\
\hline$a_{r}=\beta_{r}=1$ & & & $\chi^{2}=13.26$ & $(0.866)$ & & & $\chi^{2}=20.93$ & $(0.745)$ \\
\hline$N$ & 47250 & & 47250 & & 47250 & & 47250 & \\
\hline Log-likelihood & -28030.52 & & -27936.93 & & -28003.77 & & -27862.27 & \\
\hline
\end{tabular}

Standard errors in parentheses. ${ }^{*} p<0.1, * * p<0.05 * * * p<0.01$. For all models, the base category is the 2019 wave. $r$ is the CRRA coefficient; $a_{r}, \beta_{r}$ are the parameters of the Prelec probability weighting function; $\delta$ is the discount rate of the exponential function

As evident in Table 10, only a handful of variables are statistically significant: males are less risk averse than females and a higher conspiracy theory score is associated to higher risk aversion. Note, that a joint significance test that $a_{r}=\beta_{r}=1$, fails to reject the null indicating support for EUT over RDU.

One could also be tempted to use the cases/deaths variables as an intensity of exposure to treatment variable by exploiting the geographical dispersion of students after the curfew. Although the strategy of exploiting the geographical dispersion of students after a lockdown has been used in the literature (Lohmann et al. 2020), the vast majority of our sample of students are located inside the Athens/Piraeus metropolitan area and this proportion is virtually similar in the pre-pandemic wave in 2019 and in the 2020B wave after the curfew $(82.3 \%$ vs $83.2 \%)$. Thus, we do not observe widespread dispersion of students out of the university's region after the lockdown. Nevertheless, we also estimated a generalized difference-in-difference model (DID) where the continuous treatment variable is the number of coronavirus cases in the area where the subject is taking the survey and interacted this treatment intensity variable with the wave dummies. None of the interaction terms was statistically significant and so we did not pursue this strategy further. 
Table 9 Structural estimates with hyperbolic discounting and additional controls

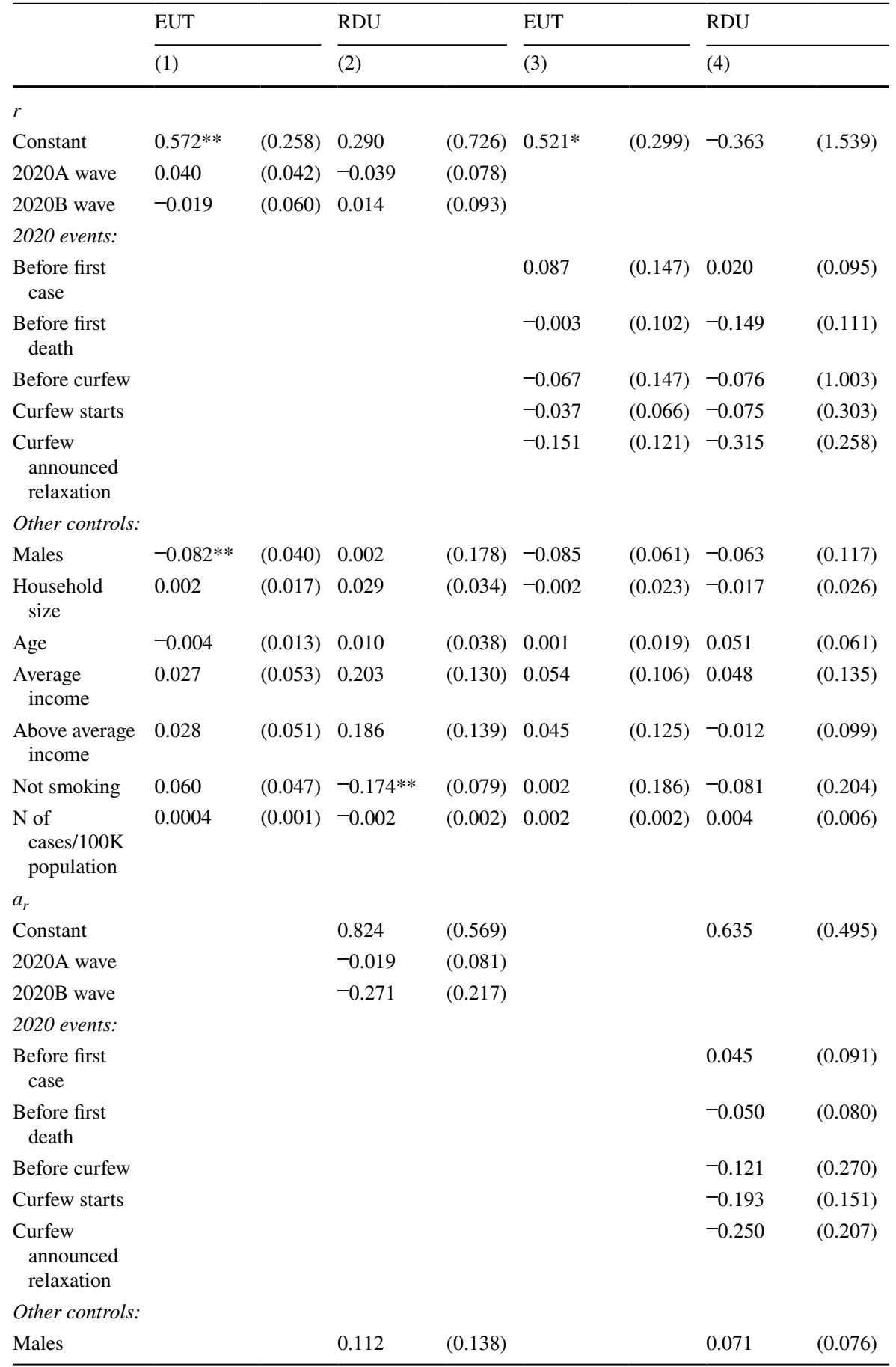


Table 9 (continued)

\begin{tabular}{|c|c|c|c|c|c|c|c|c|}
\hline \multirow{3}{*}{$\begin{array}{l}\text { Household } \\
\text { size }\end{array}$} & \multirow{2}{*}{\multicolumn{2}{|c|}{$\frac{\text { EUT }}{(1)}$}} & \multirow{2}{*}{\multicolumn{2}{|c|}{$\frac{\mathrm{RDU}}{(2)}$}} & \multirow{2}{*}{\multicolumn{2}{|c|}{$\frac{\text { EUT }}{(3)}$}} & \multirow{2}{*}{\multicolumn{2}{|c|}{$\frac{\mathrm{RDU}}{(4)}$}} \\
\hline & & & & & & & & \\
\hline & & & -0.028 & $(0.045)$ & & & -0.034 & $(0.046)$ \\
\hline Age & & & 0.008 & $(0.019)$ & & & $0.017 * *$ & $(0.007)$ \\
\hline $\begin{array}{l}\text { Average } \\
\text { income }\end{array}$ & & & 0.143 & $(0.144)$ & & & 0.065 & (0.094) \\
\hline $\begin{array}{l}\text { Above average } \\
\text { income }\end{array}$ & & & 0.037 & (0.098) & & & -0.033 & $(0.068)$ \\
\hline Not smoking & & & -0.127 & $(0.129)$ & & & -0.071 & $(0.105)$ \\
\hline $\begin{array}{l}\mathrm{N} \text { of } \\
\text { cases } / 100 \mathrm{~K} \\
\text { population }\end{array}$ & & & 0.008 & $(0.007)$ & & & 0.007 & $(0.006)$ \\
\hline \multicolumn{9}{|l|}{$\beta_{r}$} \\
\hline Constant & & & 1.536 & $(1.250)$ & & & 3.011 & $(5.091)$ \\
\hline 2020A wave & & & 0.116 & $(0.155)$ & & & & \\
\hline 2020B wave & & & -0.294 & $(0.343)$ & & & & \\
\hline \multicolumn{9}{|l|}{2020 events: } \\
\hline $\begin{array}{l}\text { Before first } \\
\text { case }\end{array}$ & & & & & & & 0.233 & $(0.715)$ \\
\hline $\begin{array}{l}\text { Before first } \\
\text { death }\end{array}$ & & & & & & & 0.527 & $(1.205)$ \\
\hline Before curfew & & & & & & & -0.211 & $(3.471)$ \\
\hline Curfew starts & & & & & & & -0.266 & $(0.651)$ \\
\hline $\begin{array}{l}\text { Curfew } \\
\text { announced } \\
\text { relaxation }\end{array}$ & & & & & & & -0.041 & $(0.939)$ \\
\hline \multicolumn{9}{|l|}{ Other controls: } \\
\hline Males & & & -0.075 & $(0.247)$ & & & 0.051 & $(0.389)$ \\
\hline $\begin{array}{l}\text { Household } \\
\text { size }\end{array}$ & & & -0.071 & $(0.067)$ & & & 0.007 & $(0.113)$ \\
\hline Age & & & -0.033 & $(0.087)$ & & & -0.187 & $(0.509)$ \\
\hline $\begin{array}{l}\text { Average } \\
\text { income }\end{array}$ & & & -0.147 & $(0.294)$ & & & 0.229 & $(0.425)$ \\
\hline $\begin{array}{l}\text { Above average } \\
\text { income }\end{array}$ & & & -0.245 & $(0.225)$ & & & 0.088 & $(0.375)$ \\
\hline Not smoking & & & 0.447 & $(0.365)$ & & & 0.518 & $(0.351)$ \\
\hline $\begin{array}{l}\mathrm{N} \text { of } \\
\text { cases/100K } \\
\text { population }\end{array}$ & & & 0.009 & $(0.010)$ & & & 0.007 & $(0.015)$ \\
\hline \multicolumn{9}{|l|}{$K$} \\
\hline Constant & 0.179 & $(0.118)$ & 0.377 & $(0.873)$ & 0.206 & $(0.164)$ & 2.509 & $(11.392)$ \\
\hline 2020A wave & -0.017 & $(0.023)$ & 0.051 & $(0.085)$ & & & & \\
\hline 2020B wave & -0.002 & $(0.029)$ & -0.039 & $(0.184)$ & & & & \\
\hline
\end{tabular}


Table 9 (continued)

\begin{tabular}{|c|c|c|c|c|c|c|c|c|}
\hline & \multicolumn{2}{|l|}{ EUT } & \multicolumn{2}{|l|}{ RDU } & \multicolumn{2}{|l|}{ EUT } & \multicolumn{2}{|l|}{ RDU } \\
\hline & (1) & & (2) & & (3) & & (4) & \\
\hline \multicolumn{9}{|l|}{2020 events: } \\
\hline $\begin{array}{l}\text { Before first } \\
\text { case }\end{array}$ & & & & & -0.045 & $(0.091)$ & -0.188 & $(0.583)$ \\
\hline $\begin{array}{l}\text { Before first } \\
\text { death }\end{array}$ & & & & & 0.005 & $(0.054)$ & 1.186 & $(6.052)$ \\
\hline Before curfew & & & & & 0.026 & $(0.088)$ & 0.552 & $(5.656)$ \\
\hline Curfew starts & & & & & 0.003 & $(0.037)$ & 0.198 & (3.016) \\
\hline $\begin{array}{l}\text { Curfew } \\
\text { announced } \\
\text { relaxation }\end{array}$ & & & & & 0.031 & $(0.078)$ & 2.046 & $(12.055)$ \\
\hline \multicolumn{9}{|l|}{ Other controls: } \\
\hline Males & 0.038 & $(0.037)$ & -0.008 & $(0.195)$ & 0.046 & $(0.063)$ & 0.477 & $(1.597)$ \\
\hline $\begin{array}{l}\text { Household } \\
\text { size }\end{array}$ & -0.009 & $(0.009)$ & -0.046 & $(0.083)$ & -0.008 & $(0.012)$ & 0.019 & $(0.228)$ \\
\hline Age & 0.004 & $(0.004)$ & -0.008 & $(0.062)$ & 0.001 & $(0.009)$ & -0.320 & (1.862) \\
\hline $\begin{array}{l}\text { Average } \\
\text { income }\end{array}$ & -0.002 & $(0.025)$ & -0.148 & $(0.404)$ & -0.015 & $(0.056)$ & -0.233 & (1.919) \\
\hline $\begin{array}{l}\text { Above average } \\
\text { income }\end{array}$ & -0.004 & $(0.023)$ & -0.136 & $(0.264)$ & -0.013 & $(0.064)$ & 0.184 & (1.014) \\
\hline Not smoking & -0.023 & $(0.024)$ & 0.314 & $(0.660)$ & -0.0002 & $(0.096)$ & 0.779 & (1.648) \\
\hline $\begin{array}{l}\mathrm{N} \text { of } \\
\text { cases/100K } \\
\text { population }\end{array}$ & 0.001 & $(0.001)$ & 0.003 & $(0.009)$ & 0.0003 & $(0.001)$ & -0.008 & $(0.072)$ \\
\hline$\mu$ & $0.130 * * *$ & $(0.003)$ & $0.119 * * *$ & $(0.006)$ & $0.130 * * *$ & $(0.004)$ & $0.121 * * *$ & $(0.007)$ \\
\hline$v$ & $0.067 * * *$ & $(0.002)$ & $0.069^{* * *}$ & $(0.003)$ & $0.067 * * *$ & $(0.002)$ & $0.068 * * *$ & $(0.004)$ \\
\hline \multicolumn{9}{|c|}{ Wald tests (joint significance): } \\
\hline $\begin{array}{l}\text { Wave/event } \\
\text { dummies }=0\end{array}$ & $\chi^{2}=1.55$ & $(0.817)$ & $\chi^{2}=3.58$ & $(0.893)$ & $\chi^{2}=2.94$ & $(0.983)$ & $\chi^{2}=7.98$ & $(0.992)$ \\
\hline$a_{r}=\beta_{r}=1$ & & & $\chi^{2}=13.01$ & $(0.877)$ & & & $\chi^{2}=17.44$ & $(0.896)$ \\
\hline$N$ & 47250 & & 47250 & & 47250 & & 47250 & \\
\hline Log-likelihood & -27989.11 & & -27903.28 & & -27957.94 & & -27828.41 & \\
\hline
\end{tabular}

Standard errors in parentheses. ${ }^{*} p<0.1, * * p<0.05 * * * p<0.01$. For all models, the base category is the 2019 wave. $r$ is the CRRA coefficient; $a_{r}, \beta_{r}$ are the parameters of the Prelec probability weighting function; $K$ is the parameter of the hyperbolic function 
Table 10 Structural estimates with coronavirus related control variables

\begin{tabular}{|c|c|c|c|c|c|c|c|c|}
\hline & \multicolumn{4}{|c|}{ Exponential discounting } & \multicolumn{4}{|c|}{ Hyperbolic discounting } \\
\hline & \multicolumn{2}{|l|}{ EUT } & \multicolumn{2}{|l|}{ RDU } & \multicolumn{2}{|l|}{ EUT } & \multicolumn{2}{|l|}{ RDU } \\
\hline & (1) & & (2) & & (3) & & (4) & \\
\hline \multicolumn{9}{|l|}{$r$} \\
\hline Constant & -0.164 & $(0.838)$ & $0.958 * * *$ & $(0.184)$ & -0.159 & $(0.787)$ & $0.942 * * *$ & $(0.230)$ \\
\hline Males & $-0.159 * *$ & $(0.075)$ & $0.157 * *$ & $(0.073)$ & $-0.159 * *$ & $(0.074)$ & $0.218^{*}$ & $(0.129)$ \\
\hline Household size & -0.078 & $(0.055)$ & 0.003 & $(0.005)$ & -0.078 & $(0.050)$ & 0.005 & $(0.008)$ \\
\hline Age & 0.037 & $(0.024)$ & -0.013 & $(0.014)$ & 0.037 & $(0.023)$ & -0.019 & $(0.022)$ \\
\hline Average income & 0.004 & $(0.139)$ & 0.024 & $(0.026)$ & -0.00005 & $(0.127)$ & 0.034 & $(0.039)$ \\
\hline $\begin{array}{l}\text { Above average } \\
\text { income }\end{array}$ & 0.013 & $(0.156)$ & 0.001 & $(0.016)$ & 0.010 & $(0.146)$ & 0.001 & $(0.023)$ \\
\hline Not smoking & 0.037 & $(0.124)$ & 0.009 & $(0.018)$ & 0.037 & $(0.127)$ & 0.012 & $(0.026)$ \\
\hline $\begin{array}{l}\mathrm{N} \text { of cases } / 100 \mathrm{~K} \\
\text { population }\end{array}$ & 0.002 & $(0.001)$ & 0.0001 & $(0.0004)$ & $0.002 *$ & $(0.001)$ & 0.0002 & $(0.001)$ \\
\hline \multicolumn{9}{|c|}{ Is social distancing effective? } \\
\hline $\begin{array}{l}\text { Neither inefficient, } \\
\text { nor efficient }\end{array}$ & 0.131 & $(0.265)$ & 0.052 & $(0.068)$ & 0.136 & $(0.265)$ & 0.076 & $(0.100)$ \\
\hline Efficient & 0.161 & $(0.265)$ & 0.033 & $(0.049)$ & 0.163 & $(0.260)$ & 0.048 & $(0.073)$ \\
\hline Very efficient & 0.090 & $(0.429)$ & 0.064 & $(0.077)$ & 0.088 & $(0.414)$ & 0.093 & $(0.112)$ \\
\hline $\begin{array}{l}\text { Close ones in high } \\
\text { risk group }\end{array}$ & -0.078 & $(0.061)$ & 0.079 & $(0.111)$ & -0.079 & $(0.061)$ & 0.130 & $(0.227)$ \\
\hline $\begin{array}{l}\text { Coronavirus stress } \\
\text { score }\end{array}$ & -0.006 & $(0.007)$ & -0.002 & $(0.003)$ & -0.006 & $(0.007)$ & -0.002 & $(0.004)$ \\
\hline $\begin{array}{l}\text { Conspiracy theories } \\
\text { score }\end{array}$ & $0.017 * *$ & $(0.007)$ & -0.004 & $(0.004)$ & $0.017^{* *}$ & $(0.007)$ & -0.006 & $(0.006)$ \\
\hline \multicolumn{9}{|l|}{$\alpha_{r}$} \\
\hline Constant & & & 0.463 & $(0.593)$ & & & 0.602 & $(1.661)$ \\
\hline Males & & & -0.029 & $(0.097)$ & & & -0.040 & $(0.287)$ \\
\hline Age & & & 0.014 & $(0.010)$ & & & 0.015 & $(0.026)$ \\
\hline Household size & & & 0.014 & $(0.049)$ & & & 0.035 & $(0.236)$ \\
\hline Average income & & & 0.032 & $(0.115)$ & & & 0.012 & $(0.368)$ \\
\hline $\begin{array}{l}\text { Above average } \\
\text { income }\end{array}$ & & & -0.080 & $(0.169)$ & & & -0.140 & $(0.730)$ \\
\hline Not smoking & & & 0.119 & $(0.183)$ & & & 0.177 & $(0.743)$ \\
\hline $\begin{array}{l}\mathrm{N} \text { of cases } / 100 \mathrm{~K} \\
\text { population }\end{array}$ & & & 0.005 & $(0.006)$ & & & 0.006 & $(0.016)$ \\
\hline \multicolumn{9}{|c|}{ Is social distancing effective? } \\
\hline $\begin{array}{l}\text { Neither inefficient, } \\
\text { nor efficient }\end{array}$ & & & -0.143 & $(0.256)$ & & & -0.236 & (1.077) \\
\hline Efficient & & & -0.057 & $(0.157)$ & & & -0.119 & $(0.743)$ \\
\hline Very efficient & & & -0.204 & $(0.293)$ & & & -0.306 & $(1.175)$ \\
\hline $\begin{array}{l}\text { Close ones in high } \\
\text { risk group }\end{array}$ & & & -0.043 & $(0.130)$ & & & -0.081 & $(0.571)$ \\
\hline $\begin{array}{l}\text { Coronavirus stress } \\
\text { score }\end{array}$ & & & -0.003 & $(0.009)$ & & & -0.004 & $(0.019)$ \\
\hline
\end{tabular}


Table 10 (continued)

\begin{tabular}{|c|c|c|c|c|c|c|c|c|}
\hline & \multicolumn{4}{|c|}{ Exponential discounting } & \multicolumn{4}{|c|}{ Hyperbolic discounting } \\
\hline & \multicolumn{2}{|l|}{ EUT } & \multicolumn{2}{|l|}{ RDU } & \multicolumn{2}{|l|}{ EUT } & \multicolumn{2}{|l|}{ RDU } \\
\hline & (1) & & (2) & & (3) & & $(4)$ & \\
\hline \multicolumn{2}{|l|}{$\begin{array}{l}\text { Conspiracy theories } \\
\text { score }\end{array}$} & & -0.012 & $(0.021)$ & & & -0.020 & $(0.090)$ \\
\hline \multicolumn{9}{|l|}{$b_{r}$} \\
\hline Constant & & & 0.289 & $(0.230)$ & & & 0.337 & $(0.539)$ \\
\hline Males & & & -0.049 & $(0.057)$ & & & -0.077 & $(0.179)$ \\
\hline Age & & & 0.005 & $(0.005)$ & & & 0.008 & $(0.014)$ \\
\hline Household size & & & -0.0005 & $(0.016)$ & & & 0.003 & $(0.042)$ \\
\hline Average income & & & 0.033 & $(0.050)$ & & & 0.028 & $(0.098)$ \\
\hline $\begin{array}{l}\text { Above average } \\
\text { income }\end{array}$ & & & -0.004 & $(0.042)$ & & & -0.014 & $(0.139)$ \\
\hline Not smoking & & & 0.078 & $(0.070)$ & & & 0.094 & $(0.203)$ \\
\hline $\begin{array}{l}\mathrm{N} \text { of cases } / 100 \mathrm{~K} \\
\text { population }\end{array}$ & & & 0.001 & $(0.001)$ & & & 0.001 & $(0.002)$ \\
\hline \multicolumn{9}{|c|}{ Is social distancing effective? } \\
\hline $\begin{array}{l}\text { Neither inefficient, } \\
\text { nor efficient }\end{array}$ & & & 0.001 & $(0.071)$ & & & -0.024 & $(0.239)$ \\
\hline Efficient & & & 0.039 & $(0.066)$ & & & 0.026 & $(0.163)$ \\
\hline Very efficient & & & -0.022 & $(0.079)$ & & & -0.052 & $(0.279)$ \\
\hline $\begin{array}{l}\text { Close ones in high } \\
\text { risk group }\end{array}$ & & & -0.047 & $(0.067)$ & & & -0.077 & $(0.250)$ \\
\hline $\begin{array}{l}\text { Coronavirus stress } \\
\text { score }\end{array}$ & & & 0.004 & $(0.004)$ & & & 0.004 & $(0.008)$ \\
\hline $\begin{array}{l}\text { Conspiracy theories } \\
\text { score }\end{array}$ & & & -0.00006 & $(0.004)$ & & & -0.0004 & $(0.011)$ \\
\hline \multicolumn{9}{|l|}{$\delta, K$} \\
\hline Constant & 1.138 & (2.609) & 0.019 & $(0.021)$ & 1.035 & $(2.184)$ & 0.027 & $(0.030)$ \\
\hline Males & 0.579 & $(1.537)$ & -0.012 & $(0.016)$ & 0.505 & $(1.266)$ & -0.017 & $(0.021)$ \\
\hline Household size & 0.293 & $(0.498)$ & & & 0.257 & $(0.409)$ & & \\
\hline Age & -0.117 & $(0.336)$ & 0.002 & $(0.001)$ & -0.102 & $(0.275)$ & 0.003 & $(0.002)$ \\
\hline Average income & 0.134 & $(0.506)$ & & & 0.137 & $(0.428)$ & & \\
\hline $\begin{array}{l}\text { Above average } \\
\text { income }\end{array}$ & -0.016 & $(0.566)$ & & & -0.001 & $(0.464)$ & & \\
\hline Not smoking & -0.017 & $(0.414)$ & 0.001 & $(0.003)$ & -0.015 & $(0.374)$ & 0.001 & $(0.005)$ \\
\hline $\begin{array}{l}\mathrm{N} \text { of cases } / 100 \mathrm{~K} \\
\text { population }\end{array}$ & -0.001 & $(0.005)$ & & & -0.001 & $(0.005)$ & & \\
\hline \multicolumn{9}{|c|}{ Is social distancing effective? } \\
\hline $\begin{array}{l}\text { Neither inefficient, } \\
\text { nor efficient }\end{array}$ & -0.254 & $(1.101)$ & -0.003 & $(0.005)$ & -0.236 & $(0.955)$ & -0.005 & $(0.008)$ \\
\hline Efficient & -0.332 & $(1.217)$ & -0.002 & $(0.004)$ & -0.297 & $(1.020)$ & -0.003 & $(0.006)$ \\
\hline Very efficient & -0.133 & $(1.370)$ & -0.005 & $(0.006)$ & -0.110 & $(1.146)$ & -0.008 & $(0.009)$ \\
\hline $\begin{array}{l}\text { Close ones in high } \\
\text { risk group }\end{array}$ & 0.450 & $(0.958)$ & -0.006 & $(0.009)$ & 0.402 & $(0.807)$ & -0.010 & $(0.016)$ \\
\hline
\end{tabular}


Table 10 (continued)

Exponential discounting Hyperbolic discounting

\begin{tabular}{llll}
\hline EUT & RDU & EUT & RDU \\
\hline$(1)$ & $(2)$ & $(3)$
\end{tabular}

\begin{tabular}{|c|c|c|c|c|c|c|c|c|}
\hline $\begin{array}{l}\text { Coronavirus stress } \\
\text { score }\end{array}$ & 0.010 & $(0.045)$ & 0.00004 & $(0.0004)$ & 0.009 & $(0.039)$ & 0.00005 & $(0.001)$ \\
\hline $\begin{array}{l}\text { Conspiracy theories } \\
\text { score }\end{array}$ & -0.052 & $(0.112)$ & 0.001 & $(0.001)$ & -0.045 & $(0.090)$ & 0.001 & $(0.001)$ \\
\hline$\mu$ & $0.141 * * *$ & $(0.009)$ & $0.100 * * *$ & $(0.010)$ & $0.141 * * *$ & $(0.009)$ & $0.109 * * *$ & $(0.024)$ \\
\hline$v$ & $0.063 * * *$ & $(0.004)$ & $0.073 * * *$ & $(0.006)$ & $0.063 * * *$ & $(0.004)$ & $0.069 * * *$ & $(0.009)$ \\
\hline \multicolumn{9}{|c|}{ Wald test (joint significance): } \\
\hline \multicolumn{3}{|l|}{$a_{r}=\beta_{r}=1$} & $\chi^{2}=20.83$ & $(0.794)$ & & & $\chi^{2}=4.11$ & $(\approx 1)$ \\
\hline$N$ & 16,650 & & 16,650 & & 16,650 & & 16,650 & \\
\hline Log-likelihood & -9640.36 & & -9527.36 & & -9632.66 & & -9517.63 & \\
\hline
\end{tabular}

Standard errors in parentheses. ${ }^{*} p<0.1,{ }^{* *} p<0.05 * * * p<0.01 . r$ is the CRRA coefficient; $a_{r}, \beta_{r}$ are the parameters of the Prelec probability weighting function; $\delta, K$ are the parameters of the exponential and hyperbolic functions, respectively

\section{Conclusions}

Risk and time preferences are key factors considered in many economic models since they have important impacts on a variety of outcomes. A growing debate in the literature is about the assumption of stability of RTPs. This is an important issue since it can have significant implications and consequences for human behavior and economic decision making. For example, RTPs can affect an individual's valuation of the future and willingness to take risks, which can then influence, among others, health and labor outcomes. Our study adds to a stream of literature that examines the effect of major negative shocks on people's RTPs. We specifically focus on undoubtedly one of the biggest negative shocks that the world has ever experienced, the COVID-19 pandemic.

While there has been an emerging set of studies that examine how risk or time preferences have evolved over the course of the pandemic (Angrisani et al. 2020; Shachat et al. 2021; Lohmann et al. 2020; Harrison et al. 2020; Gassmann et al. 2020; Li et al. 2020), this study offers several advancements. First, unlike most other studies, we jointly elicited and estimated the structural parameters for various theories of risk and time preferences from a fairly large sample of more than 300 subjects per wave (for a total of about 1,000 responses). Given that most studies are focused on samples from China and only two of them measure time preferences, our study is the only one providing structural estimates for time preferences for subjects from Europe. Furthermore, our study is unique in that we spread the data collection in each wave over a relatively long period which allowed us to record multiple key events during the timeline of the pandemic.

Using estimated structural parameters for various theories of risk and time preferences from the incentivized tasks, our results clearly indicate that there are 
no significant differences in RTPs across the different waves of our data, before and during the pandemic. Overall, our subjects exhibit intertemporal stability of risk and time preferences despite the very disruptive effect of the COVID-19 pandemic on people's lives and the global economy.

We should note that students remain a sample of convenience and students could have had better chances of shielding themselves from the risks of exposure to COVID-19 by, for example, shifting their studies at home. Other groups of subjects, have not been as fortunate. Thus, while our results hold for a student sample, we refrain from generalizing to the population.

Even though our sample is very specific, our finding is important since it suggests that RTPs may not be that malleable even amid catastrophic events such as pandemics. This can significantly simplify and help policy and welfare analyses given that these are typically conducted under the assumption that preferences are stable. A worry among economists is that instability of preferences over time could deprive economics of a clean analytical foundation for welfare analysis and policy development (Schildberg-Hörisch 2018). Our study provides evidence about the stability of preferences that will further help us in our understanding of individual decision-making and outcomes. At the very least, it tells us that RTPs are critical characteristics of human beings that can be stable over a period of time (e.g., few years) despite an exogenous shock in the form of a pandemic. Future studies should examine, however, if this stability persists in the longer term, way after an exogenous shock. It is possible that the last wave of our data has not incorporated the full impact of the financial and public health crisis brought about by the pandemic. It is important to know the longer term effect of an exogenous shock since it can help new policies predict behavioral responses more adequately.

Supplementary Information The online version contains supplementary material available at https://doi. org/10.1007/s10683-021-09727-6.

\section{References}

Andersen, S., Harrison, G. W., Lau, M. I., \& Rutström, E. E. (2008a). Eliciting risk and time preferences. Econometrica, 76(3), 583-618.

Andersen, S., Harrison, G. W., Lau, M. I., \& Rutström, E. E. (2008b). Lost in state space: are preferences stable? International Economic Review, 49(3), 1091-1112.

Andersen, S., Harrison, G. W., Lau, M., \& Rutström, E. E. (2013). Discounting behavior and the magnitude effect. Economica, 80(320), 670-697.

Andersen, S., Harrison, G. W., Lau, M. I., \& Rutström, E. E. (2014). Discounting behavior: a reconsideration. European Economic Review, 71, 15-33.

Angrisani, M., Cipriani, M., Guarino, A., Kendall, R., \& Ortiz de Zarate Pina, J. (2020). Risk preferences at the time of covid-19: An experiment with professional traders and students. CEPR Discussion Paper No., 15108, 1-33.

Anzolin, E. \& Amante, A. (2020, February 21). Coronavirus outbreak grows in northern italy, 16 cases reported in one day. Available at https://web.archive.org/web/20200816091931/https:// 
www.reuters.com/article/us-china-health-italy/coronavirus-outbreak-grows-in-northern-italy-16cases-reported-in-one-day-idUSKBN20F0UI. Last accessed on August 16, 2020.

Bu, D., Hanspal, T., Liao, Y., \& Liu, Y. (2020). Risk taking during a global crisis: evidence from Wuhan. Available at SSRN:https://ssrn.com/abstract=3559870.

Chuang, Y., \& Schechter, L. (2015). Stability of experimental and survey measures of risk, time, and social preferences: a review and some new results. Journal of Development Economics, 117, $151-170$.

Coller, M., \& Williams, M. (1999). Eliciting individual discount rates. Experimental Economics, 2(2), 107-127.

Crosetto, P., \& Filippin, A. (2013). The "bomb" risk elicitation task. Journal of Risk and Uncertainty, $47(1), 31-65$.

Drichoutis, A. C., \& Lusk, J. L. (2016). What can multiple price lists really tell us about risk preferences? Journal of Risk and Uncertainty, 53(2), 89-106.

Gassmann, X., Malézieux, A., Spiegelman, E., \& Tisserand, J.-C. (2020). Preferences after pandemics: time and risk in the shadow of Covid-19. Working paper, Burgundy School of Business.

Greiner, B. (2015). Subject pool recruitment procedures: organizing experiments with ORSEE. Journal of the Economic Science Association, 1(1), 114-125.

Harrison, G. W., Hofmeyr, A., Kincaid, H., Monroe, B., Ross, D., Schneider, M., \& Swarthout, J. T. (2020). Subjective beliefs and economic preferences during the COVID-19 pandemic. CEAR $W P, 2020,22$.

Harrison, G. W., Lau, M. I., \& Williams, M. B. (2002). Estimating individual discount rates in Denmark: a field experiment. The American Economic Review, 92(5), 1606-1617.

Harrison, G. W., Lau, M. I., \& Yoo, H. I. (2020). Risk attitudes, sample selection, and attrition in a longitudinal field experiment. The Review of Economics and Statistics, 102(3), 552-568.

Harrison, G. W., \& Swarthout, J. T. (2014). Experimental payment protocols and the bipolar behaviorist. Theory and Decision, 77(3), 423-438.

Holt, C. A. (1986). Preference reversals and the independence axiom. The American Economic Review, 76(3), 508-515.

Holt, C. A., \& Laury, S. K. (2002). Risk aversion and incentive effects. The American Economic Review, 92(5), 1644-1655.

Ikeda, S., Yamamura, E., \& Tsutsui, Y. (2020). COVID-19 enhanced diminishing sensitivity in prospect-theory risk preferences: a panel analysis. Discussion Paper No. 1106, The Institute of Social and Economic Research, Osaka University.

Li, Z., Lin, P.-H., Kong, S.-Y., Wang, D., \& Duffy, J. (2021). Conducting large, repeated, multi-game economic experiments using mobile platforms. PLOS ONE, 16(4), e0250668.

Lohmann, P., Gsottbauer, E., You, J., \& Kontoleon, A. (2020). Social preferences and economic decisionmaking in the wake of COVID-19: experimental evidence from China. Available at SSRN:https:// ssrn.com/abstract $=3705264$.

Luna, R. (2020, March 5). Coronavirus: il paziente tedesco. Available at https://web.archive.org/web/ 20200816091422/https://rep.repubblica.it/pwa/generale/2020/03/05/news/coronavirus-250377117/. Last accessed on August 16, 2020.

Mazur, J. E. (1984). Tests of an equivalence rule for fixed and variable reinforcer delays. Journal of Experimental Psychology: Animal Behavior Processes, 10(4), 426-436.

Prelec, D. (1998). The probability weighting function. Econometrica, 66(3), 497-528.

Quiggin, J. (1982). A theory of anticipated utility. Journal of Economic Behavior \& Organization, 3(4), 323-343.

Read, D., Frederick, S., Orsel, B., \& Rahman, J. (2005). Four score and seven years from now: the date/ delay effect in temporal discounting. Management Science, 51(9), 1326-1335.

Schildberg-Hörisch, H. (2018). Are risk preferences stable? Journal of Economic Perspectives, 32(2), 135-54.

Shachat, J., Walker, M. J., \& Wei, L. (2021). The impact of an epidemic: experimental evidence on preference stability from wuhan. AEA Papers and Proceedings, 111, 302-06.

Snowberg, E., \& Yariv, L. (2021). Testing the waters: behavior across participant pools. American Economic Review, 111(2), 687-719.

StataCorp (2013). Stata user's guide release 13. College Station, Texas, USA: Stata Press. 
Stigler, G. J., \& Becker, G. S. (1977). De Gustibus Non Est Disputandum. The American Economic Review, 67(2), 76-90.

Publisher's Note Springer Nature remains neutral with regard to jurisdictional claims in published maps and institutional affiliations. 